auch deutlich die Problemstrukturen auf den regionalen Wohnungsmärkten, wodurch die Wohnungs- und Bauwirtschaft bereits von sich aus auf Leerstandsrisiken und veränderte Wohnraumbedarfe reagiert.

\title{
7.2 Hessen: Barrierefreiheit trotz angespannter Wohnungsmärkte?
}

Im Folgenden wird die politische Steuerung zum barrierefreien bzw. -reduzierten Wohnraum in Hessen analysiert. Nach den Instrumenten und InstrumentenAlternativen (Kapitel 7.2.1) sind die aus den hessischen Interviews herausgearbeiteten Problemstrukturen zu erörtern (Kapitel 7.2.2). Der Rolle von situativen Aspekten widmet sich anschließend Kapitel 7.2.3, der Rolle der institutionellen Regelungen Kapitel 7.2.4. Den Akteuren und ihren Handlungen kommt entsprechend der Handlungsorientierung des AEP ein besonderes Gewicht zu. Dafür arbeitet Kapitel 7.2.5 die Interessen, Ressourcen und Strategien von außerparlamentarischen Interessenvertretungen, parteipolitischen Akteuren und der Ministerialverwaltung heraus. Am Ende erfolgt eine Zusammenfassung der empirischen Erkenntnisse (Kapitel 7.2.6).

\subsubsection{Instrumente und Instrumenten-Alternativen}

Zunächst ist der zum Jahr 2019 bestehende Policy-Mix zu identifizieren. Die politischen Diskussionen zu Instrumenten-Alternativen nach Typ 1 sind unter »Akteure und ihren Handlungen « dargestellt, dort geht es um Veränderungen in den bestehenden PolicyAusprägungen (vgl. Kapitel 7.2.5). Weitere Instrumenten-Alternativen werden direkt hier im Anschluss diskutiert, verstanden als ergänzende - Typ 2 - oder ersetzende Typ 3 - Maßnahmen des bestehenden Policy-Mix. Dabei kann es sich um bundespolitische oder kommunale Maßnahmen handeln, ferner um die staatliche Bereitstellung von Wohnraum und kooperative Instrumente wie Bündnisse oder eine weitgehend freiwillige Selbstregelung der Wohnungs- und Bauwirtschaft (vgl. Kapitel 4.2).

Die drei Policies im Überblick

Im Folgenden werden die hessischen Policy-Ausprägungen zum Bauordnungsrecht, zur sozialen Wohnraumförderung und zur Wohnberatung dargestellt. Diese bilden den bestehenden Policy-Mix und damit die Basis für darauffolgende InstrumentenAlternativen. Zusammen mit einer anschließenden Betrachtung der zusätzlich umgesetzten Instrumenten-Alternativen ergibt sich ein Bild der politischen Steuerung vom barrierefreien bzw. -reduzierten Wohnraum in Hessen.

\section{$\S 54$ Abs. 1 der Landesbauordnung (HBO)}

Die hessische Bauordnung wurde zuletzt im Sommer 2018 novelliert und definiert in $\$$ 54 Absatz 1 das barrierefreie Bauen für Wohnungen:

»In Cebäuden mit mehr als zwei Wohnungen müssen mindestens 20 Prozent der Wohnungen barrierefrei erreichbar und zugänglich sein, höchstens jedoch 20 Wohnungen. In diesen Wohnungen müssen die Wohn- und Schlafräume, eine Toilette, ein Bad sowie 
die Küche oder die Kochnische barrierefrei zugänglich sein. Die Räume nach Satz 2 sind so herzustellen und vorzubereiten, dass sie für eine barrierefreie Nutzung leicht einzurichten und auszustatten sind. Soweit die Wohnung über einen Freisitz verfügt, muss dieser von der Wohnung aus schwellenlos erreichbar sein [...] «(HMWEVW 2018a: 53f.).

Abweichend von der Musterbauordnung wird eine 20-Prozent-Regelung definiert, zudem sind neben der barrierefreien Erreichbarkeit - bis zur Wohneingangstür - auch die Zugänglichkeit - inklusive der Wohneingangstür - sowie schwellenlose Freisitze festgeschrieben. Die genannten Räume wiederum müssen barrierefrei zugänglich und für eine nachträgliche barrierefreie Nutzung leicht einzurichten sein. Das Bundesmuster fordert hier direkt »barrierefreie« Wohnräume (vgl. Kapitel 6.1.2).

Die hessische Verwaltungsvorschrift Technische Baubestimmungen wiederum orientiert sich stark an der Muster-Verwaltungsvorschrift. So sind die Abschnitte 4.3.6 zu Treppen und $4.4 \mathrm{zu}$ Warnen/Orientieren/Informieren/Leiten ebenso von der Einführung ausgenommen wie alle Anforderungen mit der Kennzeichnung »R« für rollstuhlgerecht. Abweichend von dem Bundesmuster werden Vorgaben für die schwellenlose Erreichbarkeit der Freisitze definiert (HMWEVW 2018b: 63, vgl. auch Kapitel 6.1.3).

Bemerkenswert ist in Hessen das ebenfalls im Sommer 2018 eingeführte Planungskonzept zum Barrierefreien Bauen (auch: »Barrierefrei-Konzept«, vgl. IP 52: 8ff.; IP 54: 23). Durch einen Bauvorlagenerlass ist der entsprechende Vordruck BAB 35 im Rahmen des Baugenehmigungsverfahren einzureichen. Er soll nachweisen, dass den bauordnungsrechtlichen Vorgaben zur Barrierefreiheit nachgekommen wird (HMWEVW 2019b: 1; HMWEVW 2020a).

\section{Wohnraumförderung}

Die Förderprogramme in Hessen basieren auf dem Wohnraumfördergesetz des Jahres 2012. Als Zielgruppe benannt sind darin Haushalte, die sich »am Markt nicht angemessen mit Wohnraum versorgen können « sowie Haushalte, die ihren bestehenden Wohnraum an die »Erfordernisse des demografischen Wandels« anpassen (Hessischer Landtag 2012: 4). Auf dieser Basis erstellt das Land Förderrichtlinien, aus denen die einzelnen Förderprogramme hervorgehen und durch die WIBank als hessische Landesförderbank ausgegeben werden. Abbildung 27 zeigt eine Übersicht derjenigen Förderprogramme, die barrierefreies bzw. barrierereduziertes (Um)Bauen adressieren oder als dezidierte Zielgruppe ältere Menschen bzw. Menschen mit Behinderungen fassen.

In der Eigentumsförderung unterstützen das Hessen-Darlehen und das HessenBaudarlehen den Neubau sowie den Erwerb von selbstgenutzten Immobilien. Bevorzugt werden Haushalte mit Kindern sowie Haushalte mit einem besonderen baulichen Bedarf durch eine Behinderung (WIBank Hessen 2019a; WIBank Hessen 2019c). Zur Nutzergruppe schätzt eine Interviewpartnerin aus der WIBank: »Also beim HessenBaudarlehen, Hessen-Darlehen geht es, würde ich sagen, 95 zu 5 um Familien mit Kindern « (IP 17: 120). Einschlägiger ist der behindertengerechte Umbau, dieses Programm gibt Kostenzuschüsse bis zu 12.500 Euro für den Umbau bestehenden Wohnraums aus. Der Zuschuss beträgt bis zu 50 Prozent der förderfähigen Kosten, sodass Maßnahmen in Höhe von bis zu 25.000 Euro förderfähig sind (HMUKLV 2014; WIBank Hessen 2020a). Betrug das Fördervolumen hier zunächst eine Million Euro pro Jahr, wurde es 2015 auf 
Abbildung 27: Hessische Wohnraumförderprogramme mit Bezugnahme zum barrierefreien bzw. -reduzierten Wohnraum (eigene Darstellung)

\begin{tabular}{|c|}
\hline Eigentumsförderung \\
\hline -Hessen-Darlehen und Baudarlehen \\
-Behindertengerechter Umbau von \\
selbstgenutztem Wohneigentum \\
-Maßnahmen zur Barrierereduzierung bei \\
Wohnungseigentümergemeinschaften (KfW- \\
Altersgerecht Umbauen) \\
\end{tabular}

\begin{tabular}{|c|}
\hline \multicolumn{1}{|c|}{ Mietwohnraumförderung } \\
\hline • KfW-Altersgerecht Umbauen zzgl. \\
Zinsvergünstigung \\
- Soziale Mietwohnraumförderung: Geringe \\
Einkommen und mittlere Einkommen \\
- Soziale Mietwohnraumförderung: \\
Modernisierung \\
- Kommunalinvestitionsprogramm (KIP) - \\
Programmteil Wohnraum \\
\hline
\end{tabular}

zwei Millionen verdoppelt (IP 10: 28; HMUKLV 2017: 12). Letztlich reicht die WIBank auch das KfW-Programm "Altersgerecht Umbauen« an Wohnungseigentümergemeinschaften weiter (WIBank Hessen 2019b).

In der Mietwohnraumförderung wird »Altersgerecht Umbauen« ebenfalls weitergegeben und um eine Zinsvergünstigung auf den KfW-Zins ergänzt (WIBank Hessen 2020c). Darüber hinaus gibt das Land in der Wohnraumförderung für geringe und mittlere Einkommen einen zusätzlichen Zuschlag von 150 Euro pro $\mathrm{m}^{2}$ für rollstuhlgerechten Wohnraum und ein Zusatzdarlehen für den Einbau eines Aufzugs von $3.000 \mathrm{Eu}$ ro je geförderter Wohnung (HMUKLV 2018: 10). Vor der Überarbeitung der Richtlinie im Sommer 2018 wurde auch der Bau von eingeschränkt mit dem Rollstuhl nutzbaren Wohnungen über einen achtprozentigen Mehrflächen-Zuschlag und 50 Euro pro $\mathrm{m}^{2}$ unterstützt (IP 17: 11ff.; IP 52: 10ff.). Bei der Modernisierung sind Maßnahmen zur "Verbesserung der baulichen Eignung einer Wohnung für ältere Menschen oder Menschen mit Behinderungen « förderfähig (HMUKLV 2018: 16). Neben der Wohnungs- und Bauwirtschaft nehmen in zunehmendem Maße auch soziale Träger die Mietwohnraumförderung etwa für betreute Wohnanlagen wie Seniorenresidenzen in Anspruch (IP 17: 125ff.).

Die letzte hier dargestellte Förderung ist der Programmteil Wohnraum im Kommunalinvestitionsprogramm (KIP), basierend auf einer Richtlinie des Jahres 2016 und zum Zeitpunkt der Untersuchung gerade überführt in das Wohnrauminvestitionsprogramm (WIP). Dieses Programm sollte Kommunen ursprünglich bei der Unterbringung von Menschen mit Fluchthintergrund unterstützen. Letztlich sind die Förderkonditionen vergleichbar mit der regulären Mietwohnraumförderung, es findet sich im KIP lediglich noch der Zuschlag von 50 Euro pro $\mathrm{m}^{2}$ auf barrierefreien Wohnraum ohne R-Anforderung, der aus der Richtlinie zur Wohnraumförderung im Sommer 2018 entfallen ist (WIBank Hessen 2020b; HMUKLV 2016b: 219; IP 57: 25).

Insgesamt ist die hessische Förderlandschaft zum barrierefreien bzw. -reduzierten Wohnraum ausdifferenziert. Sie berücksichtigt diese Kriterien sowohl in der Eigentumsförderung als auch in der Mietwohnraumförderung, dabei je sowohl im Neubau als auch im Umbau. Gleichzeitig wendet ein Gesprächspartner der Landesförderbank ein: »Wir haben im Moment [...] im Angebot 119 Förderprodukte oder Förderprogramme. Und das Thema barrierefreies Bauen ist eines davon. Gut zwei Millionen Euro Zuschusshöhe [...] vor dem 
Hintergrund eines normalen Neugeschäfts von mehr als zwei Milliarden. Also, es ist in der Tat eher ein Orchideen-Thema« (IP 10: 28). Diese Aussage bezieht sich auf das Zuschussprogramm für den behindertengerechten Umbau, verdeutlicht aber die in der Landesförderung gesetzten Schwerpunkte für den barrierefreien bzw. -reduzierten Wohnraum.

\section{Wohnberatungsstellen zur Wohnungsanpassung}

Bei der Wohnberatung zur Wohnungsanpassung ist zwischen den einzelnen Bundesländern umstritten, inwieweit es sich überhaupt um eine politische Steuerung handelt (vgl. Kapitel 6.3.3). In Hessen fördert das Sozialministerium seit 2002 eine Hessische Fachstelle für Wohnberatung (HFW) in Kassel. Ihre Einrichtung basierte auf dem Bundesmodellprogramm »Selbstbestimmt Wohnen im Alter« der Jahre 1998 bis 2001 vom damaligen Familienministerium. Das Ziel war die »Entwicklung und Etablierung einer landesweiten Unterstützungsstruktur für Wohnberatung als vernetzte Dienstleistung (HFW 2002: 3, vgl. auch IP 16: 17). Träger ist die Arbeiterwohlfahrt des Bezirksverbands HessenNord, wobei die Förderung jährlich neu zu beantragen ist. Belief sie sich anfangs auf insgesamt eine 100-Prozent-Stelle zuzüglich 25 Prozent Verwaltungsarbeit, wurde sie in der Zwischenzeit auf zwei Personen à 75 und 100 Prozent aufgestockt (HFW 2002: 11; IP 16: 9ff.).

Im Rahmen von zunächst dreitätigen und im Jahr 2019 sechstätigen Schulungen werden hauptamtliche sowie ehrenamtliche Wohnberater*innen durch die HFW aus- und weitergebildet. Als Zielgruppe gelten neben Sozialstationen auch Verbände, aber insbesondere kommunale Beratungsstellen der Altenhilfe und Sozialplanung (HFW 2002: 4; IP 16: 17ff.). Die Lehrgänge orientieren sich an den Qualitätskriterien der Bundearbeitsgemeinschaft Wohnungsanpassung e.V. und finden in Kooperation mit hessischen Handwerkskammern statt (HMSI 2019: 7). Nach Aussage des Sozialministeriums wurden bis Ende $2018 \mathrm{ca} .350$ hauptamtliche und 310 ehrenamtliche Wohnberater"innen ausgebildet, womit »ein nahezu flächendeckendes Netz an Wohnberatungsangeboten in Hessen vorhanden « sei (HMSI 2020b). Die meisten der Beratungsstellen sind im Rahmen von Seniorenberatungen oder Pflegestützpunkten direkt bei den Kommunen angesiedelt. Diese kommunale Aktivität wird durch die Landesfachstelle in ihrer Schulungs- und Koordinationsfunktion unterstützt. Entsprechend liegt es aber vor allem in der Hand der lokalen Akteure, wie intensiv sie diese Aufgabe wahrnehmen (IP 14: 14ff.; IP 18: 60ff., 160; IP 18: 69, 162; IP 20: 45ff.; IP 54: 3).

\section{Instrumenten-Alternativen}

Der bislang untersuchte Policy-Mix wird ergänzt um Maßnahmen, zu denen Hinweise im empirischen Material in Hessen gefunden wurden. Der Schwerpunkt liegt dabei auf der staatlichen Bereitstellung von Wohnraum und verschiedenen kooperativen Instrumenten (vgl. Kapitel 4.2.1), diese können jeweils vom Land, aber auch vom Bund oder von den hessischen Kommunen initiiert werden. Inwieweit handelt es sich dabei um potentielle oder tatsächlich praktizierte Policies? Und liegt eine ergänzende Maßnahme - als Instrumenten-Alternative, Typ 2 - oder eine den bisherigen Policy-Mix ersetzende Maßnahme - als Instrumenten-Alternative, Typ 3 - vor (vgl. Kapitel 4.2.2)? 
Staatliche Bereitstellung von Wohnraum

Die staatliche Bereitstellung von Wohnraum geschieht in Hessen einerseits durch kommunale Wohnungsunternehmen, andererseits durch die Nassauische Heimstätte, an der das Land zu 59 Prozent Gesellschafter ist (Nassauische Heimstätte 2020). Generell schreiben die Interviewpartner*innen staatlichen Wohnungsunternehmen einen politischen Auftrag zur Erfüllung politischer Zielvorgaben zu (IP 20: 48; IP 48: 16; IP 50: 20), wobei die tatsächliche Aktivität eher zurückhaltend sei: »Wenn man sich da anguckt, [...] wie viele Sozialwohnungen so eine Nassauische Heimstätte hat, kriegt man auch so ein bisschen Fragezeichen, was eigentlich Aufgabe von öffentlichen Wohnungsbaugesellschaften ist « (IP 50: 20, vgl. auch IP 7: 18ff., 42). Auch die ABG Frankfurt Holding mit der Stadt Frankfurt a.M. als Mehrheitsgesellschafterin handele beim sozial geförderten Wohnungsbau sowie spezifisch beim barrierefreien bzw. -reduzierten Wohnraum eher reserviert (IP 7: 36; IP 18: 26f., 75ff.). Dieser Eindruck verstärkt sich dadurch, dass trotz vermehrter Anstrengungen nur ein einziges kommunales hessisches Wohnungsunternehmen zu einem Interview bereit war (vgl. Kapitel 5.2.2). Insofern muss die staatliche Bereitstellung von entsprechend ausgestattetem Wohnraum eher als potentielle denn tatsächlich genutzte Instrumenten-Alternative verstanden werden.

Kooperative Instrumente

Kooperative Instrumente wurden als eine weiche Form der politischen Steuerung eingeführt (vgl. Kapitel 4.2.1). Hierunter fällt die im Jahr 2015 von der hessischen Landesregierung initiierte Allianz für Wohnen, denn sie bringt alle »wesentlichen Akteure, die mit Wohnungsbau zu tun haben « zusammen und soll neue wohnungspolitische Strategien entwickeln (IP 57: 29). Der Allianz gehören neben der Landesregierung in Form der zuständigen Fachministerien die Verbände der Wohnungs- und Bauwirtschaft, kommunale Spitzenverbände, Kammern und der Mieterbund an. Auch die WIBank als Landesförderinstitut und die Liga der Freien Wohlfahrtspflege in Hessen e.V. sind involviert (HMWEVW 2019a: 2ff.). Inwiefern dieses exekutiv eingerichtete Gremium in den politischen Prozessen zum barrierefreien bzw. -reduzierten Wohnraum eine Rolle spielt, zeigen die folgenden Analysen (vgl. Kapitel 7.2.5). Darüber hinaus finden sich in Hessen außerhalb des politisch-administrativen Raums weitere wohnungspolitische Bündnisse. So repräsentiert »\#Mietenwahnsinn-Hessen« die Nachfrageseite nach Wohnraum setzt sich vor allem für bezahlbaren Wohnraum im Rhein-Main-Gebiet ein (\#Mietenwahnsinn-Hessen 2020). Das »Bündnis für Mehr Bauland« als Zusammenschluss verschiedener Industrie- und Wirtschaftsverbände sowie Kammern fordert die stärkere Ausweisung von Bauland als »Faktor zur Sicherstellung der Zukunftsfähigkeit der Region" und um »die gestiegene Flächenkonkurrenz zwischen Wohnen und Gewerbe zu managen (IHK Frankfurt a.M. 2020, vgl. auch Bündnis für mehr Bauland 2020). Diese Formate scheinen in den politischen Prozessen zum barrierefreien bzw. -reduzierten Wohnraum allerdings nicht auf, weshalb sie im Folgenden nicht weiter berücksichtigt werden. Sie unterstreichen vielmehr die gegenwärtige Schwerpunktsetzung auf bezahlbaren Wohnraum in der hessischen wohnungspolitischen Diskussion.

Nicht nur Bündnisse mit oder ohne staatliche Beteiligung, sondern auch die wirtschaftliche Selbstregelung wird unter kooperativen Instrumenten gefasst (vgl. Kapi- 
tel 4.2.1). So erklärt ein Vertreter der Wohnungs- und Bauwirtschaft, es würde bereits durch die alternde Kauf- und Mieterstruktur auf entsprechend neue Wohnraumbedarfe reagiert, »auch ohne, dass die Politik da jetzt tätig werden muss oder tätig wird (IP 12: 6). Demgegenüber schätzen verschiedene Interviewpartner*innen das Interesse der Wohnungs- und Bauwirtschaft zur Bereitstellung von barrierefreiem bzw. -reduziertem Wohnraum allerdings aufgrund der angespannten Wohnungsmärkte als gering ein (IP 18: 8; IP 49: 41; IP 54: 81, vgl. Kapitel 7.3.2). Ein Akteur aus der kommunalen Wohnraumförderung erklärt:

»Die Investoren [...] haben vor allem eines im Blick, und das ist die Rendite. Die haben überhaupt kein Interesse daran, freiwillig mehr Geld zu investieren, weil sie glauben, dass sie dann die Wohnung loswerden. Sie werden die Wohnung auch so los [...]. Also, es gibt keinerlei Interesse von Wohnungsbaugesellschaften oder größeren Bauunternehmen Richtung barrierefreies Wohnen« (IP 51: 33f.).

Für den Neubau sei eine sogenannte barrierearme Bauweise im hochpreisigen Segment inzwischen Standard, die Umsetzung einzelner barrierefreier Kriterien ließe sich unter dem Gesichtspunkt »Komfort « vermarken. Insbesondere relativ kostenneutrale Umsetzungen wie das weitgehend schwellenfreie Bauen oder Türbreiten von 90 Zentimetern hätten sich etabliert (IP 7: 6ff.; IP 8: 43; IP 20: 34; IP 46: 127; IP 48: 6; IP 54: 69ff.). Für die geringen und mittleren Einkommen seien die Aktivitäten indessen eher verhalten. Auch wenn die soziale Wohnraumförderung als Schnittstelle zwischen politischer Anreizsteuerung und wirtschaftlicher Selbstregelung fungiere, sei diese im Rhein-MainGebiet für die Wohnungs- und Bauwirtschaft nicht sonderlich attraktiv (IP 7: 18; IP 52: 8). Die Förderkriterien der WIBank, in denen Wohnraum nach DIN 18040-2 ohne R-Anforderung nicht mehr bezuschusst wird, zeigen zudem exemplarisch, wie eine politische Förderung die wirtschaftliche Selbstregelung unterstützen oder hemmen kann (IP 52: 6, 14).

Für den Gebäudebestand gelten zunächst Dienstleistungen im Rahmen des Sozialmanagements als wirtschaftliche Selbstregelung. So bieten viele Wohnungsunternehmen nicht nur Wohnbetreuungen oder Besucherdienste an, sondern lassen auch eigene Wohnberater*innen ausbilden (IP 16: 97ff.; IP 18: 162; IP 54: 80f.; IP 55: 18, 51). Gleichzeitig erklärt ein kommunales Wohnungsunternehmen, dieses Angebot werde von Unternehmensseite nicht aktiv beworben: »[W]eil wir ein bisschen befürchten, dass das aus dem Ruder laufen könnte. Weil das immer sehr umfangreiche Arbeiten sind und wir einfach sehr viele ältere Mieter auch haben « (IP 55: 11ff., vgl. auch IP 54: 80f.). Und zwei Wohnberaterinnen berichten von Widerständen in der Zusammenarbeit mit Wohnungsunternehmen: Angesichts der hohen Wohnraumnachfrage seien Umbaumaßnahmen für die Angebotsseite von Wohnraum wenig attraktiv (IP 18: 169ff., 136ff.; IP 54: 3). Insbesondere die im Bundesgesetzbuch formulierte Sonderkaution für den Rückbau sei hier problematisch, da von den Mieter*innen eine entsprechende Kaution für den späteren Rückbau verlangt werden könne (vgl. auch IP 14: 48ff.; IP 18: 75; IP 20: 26). Während einige Wohnungsunternehmen von dieser Regelung Gebrauch machen, verzichten andere darauf (IP 54: 83). Generell fehlten im Bestandsumbau vielfach Standards in den Wohnungsunternehmen, womit die Kooperationsbereitschaft immer von den einzelnen Techniker*innen abhänge (IP 54: 81ff., vgl auch IP 18: 148ff.). 
Die Heterogenität in der wohnungs- und bauwirtschaftlichen Beschäftigung mit barrierefreien bzw. -reduzierten Standards soll an einem besonders aktiven Beispiel verdeutlicht werden: der Hofheimer Wohnungsbau GmbH (HWB) zwischen Wiesbaden und Frankfurt a.M. Hieran zeigt sich gut die Verknüpfung politischer Förderung und wirtschaftlicher Selbstregelung. So wurde der Hofheimer Stadtteil Marxheim von 2015 bis 2017 als Modellregion Inklusion über den hessischen Aktionsplan zur Umsetzung der UN-Behindertenrechtskonvention gefördert. Mit dem Schwerpunkt »Wohnen und Quartier« entstand eine Musterwohnung, die barrierereduziert und bezahlbar umgebaut worden ist (HWB Hofheim 2017: 4ff.). Nach Ablauf des Projekts vermietet die HWB diese Wohnung als Trainingswohnung für Schüler"innen mit Behinderungen, um sich auf ein selbstständiges Leben vorzubereiten (HWB Hofheim 2020a). Auch darüber hinaus engagiert sich das Wohnungsunternehmen über Projekte wie »Wir am Klingenborn«. Hier entstehen im seniorengerechten Wohnen sowohl freifinanziert als auch gefördert barrierefreie, teils uneingeschränkt und teils eingeschränkt mit dem Rollstuhl nutzbare Wohnungen. Und neben Mehrgenerationen-Wohnen wird eine selbstbestimmte, ambulant betreute Demenz-Wohngemeinschaft eingerichtet. Das Bauprojekt wird über das Bundesmodellprogramm »Gemeinschaftlich wohnen, selbstbestimmt leben« gefördert (HWB Hofheim 2020b: 2). Derartige innovative Projekte der wirtschaftlichen Selbstregelung wären auch von engagierten Wohnungsunternehmen nur schwerlich ohne eine politische finanzielle Förderung umsetzbar.

Der Planungsseite von Architekt"innen und Bauingenieur*innen wird von verschiedenen Interviewpartner*innen ein geringes Interesse am barrierefreien Bauen und damit keine Aktivität in der wirtschaftlichen Selbstregelung unterstellt: »Die Architektenkammer hat kein Interesse daran, dass sich das Bauen verkompliziert. Und die Barrierefreiheit ist ein Gestaltungsaspekt, der sehr häufig Gestaltungen [...] im Wege steht « (IP 46: 57). Bauordnungsrechtliche Vorgaben würden eher als Mehrarbeit wahrgenommen (IP 46: 90ff.; IP 47: 4; IP 54: 11, 63) und insgesamt falle das fachliche Wissen zum barrierefreien Bauen sehr unterschiedlich aus, was auch auf die mangelnde verpflichtende Verankerung im Studium zurückzuführen sei (IP 14: 8; IP 15: 13; IP 17: 29). ${ }^{1}$

Für das Handwerk wurde bereits gezeigt, dass die Hessische Fachstelle für Wohnberatung mit zwei Handwerkskammern kooperiert (vgl. vorherige Ausführungen). Im Rahmen eines zweitätigen Seminars können sich Handwerker"innen zur Fachkraft »Barrierefrei Planen und Bauen« ausbilden lassen, wofür der Betrieb letztlich das Zertifikat »Generationenfreundlicher Betrieb« als bundesweit abgestimmtes Logo vom Zentralverband des Deutschen Handwerks erwirbt (IP 47: 6, 13ff.; ZDH 2020). Dennoch berichtet eine Wohnberaterin von Schwierigkeiten, für kleinteilige barrierereduzierende Maßnahmen Handwerker*innen zu finden: "Bei uns ist das so zäh, [...] das sind teilweise schon relativ engagierte Handwerker, die diese kleinen Aufträge da machen möchten. Ältere Handwerker, die sich bei der Handwerkskammer zu barrierefreiem Umbau weitergebildet haben« (IP 18: 137ff.). Und auch der Vertreter einer Handwerkskammer beschreibt das 
Interesse vieler Betriebe durch die Vielzahl der am Umbau beteiligten Gewerke und die gegenwärtige Marktlage als »noch vielleicht etwas unterentwickelt (IP 47: 6).

Insgesamt ist die wirtschaftliche Selbstregelung zum barrierefreien bzw. -reduzierten Wohnraum in Hessen äußerst divers. Teils werden entsprechende Standards bereits als Marktsegment erschlossen, aber gleichzeitig ist die Situation auf den Wohnungsmärkten insbesondere im Rhein-Main-Gebiet für die Angebotsseite von Wohnraum äußerst komfortabel. Sofern es sich aus ökonomischen oder normativen Argumenten nicht rentiert, ist die Selbstregelung in diesem Teilbereich eher zurückhaltend und in keinem Fall systematisch.

Weitere kommunale Instrumenten-Alternativen

Neben der staatlichen Bereitstellung von Wohnraum und kooperativen Instrumenten beschreiben die Interviewpartner*innen verschiedene kommunale Handlungsspielräume zum barrierefreien bzw. -reduzierten Wohnraum. So seien flächendeckende Vorgaben zur Barrierefreiheit angesichts der landesweit heterogenen Wohnungsmärkte problematisch, Konzeptvergaben und Bebauungspläne werden als Alternativen angeführt: "Wenn der Immobilienentwickler es nicht von selbst sieht, dann kann ich als Politik - durch städtebauliche Verträge-, kann ich solche Maßnahmen setzen « (IP 49: 13). Diese Einschätzung wird sowohl von Seiten der Behindertenverbände als auch der Bauwirtschaft prinzipiell bestätigt und kommunale Regelungen einer landesweiten Quotierung vorgezogen (IP 12: 118; IP 46: 85ff.; IP 48: 19ff.). Beides gilt bislang aber eher als potentielles Steuerungsinstrument denn als bereits praktizierte Maßnahme (IP 7: 46; IP 18: 6, 90ff.; IP 19: 45ff.; IP 20:34, 50ff.; IP 50: 20; IP 55: 63). Zudem stellt sich die Frage, ob diese kommunale Steuerung die bauordnungsrechtlichen Regelungen ersetzen würde oder die Bauordnung als Mindeststandard gilt, auf den die Kommunen je nach Bedarf aufbauen können.

Ergänzend zur WIBank verfügen einige Kommunen über eigene Förderprogramme. Frankfurt etwa unterstützt über die sogenannten Förderwege 1 und 2 den Neubau von Mietwohnungen. Hier gibt es ähnlich wie über die WIBank WohnflächenZuschläge für rollstuhlgerechten Wohnraum, im Förderweg 1 für geringe Einkommen auch nach wie vor für barrierefreie Wohnungen ohne R-Anforderung (Stadtplanungsamt Frankfurt a.M. 2017: 2f.; Stadtplanungsamt Frankfurt a.M. 2018). Auch bei der Modernisierung sind Maßnahmen zur besseren barrierefreien Erreichbarkeit und Nutzbarkeit von Wohnungen förderfähig (Stadtplanungsamt Frankfurt a.M. 2014). Neben Frankfurt verfügt bspw. auch Darmstadt über eine zum Land komplementäre Wohnraumförderung, wiederum mit spezifischen Förderkriterien zur Barrierefreiheit (Amt für Wohnungswesen Darmstadt 2018). Einschränkend ist zu erwähnen, dass eine kommunale Wohnraumförderung mutmaßlich nicht für alle und insbesondere nicht für kleinere, finanzschwächere Kommunen leistbar ist (vgl. IP 47: 54). Eine weniger finanzintensive Aktivität liegt in kommunalen Beratungsstrukturen wie Senioren- oder Pflegestützpunkten. In diesem Rahmen bieten hessische Kommunen vielfach Wohnberatungen an (IP 14: 14; IP 16: 60; IP 20: 46ff.; IP 49: 17ff.; IP 54: 3). Somit lässt sich hier von einer vielerorts bereits realisierten Instrumenten-Alternative sprechen. Ergänzend zur koordinierenden und ausbildenden Funktion der Hessischen Fachstelle leisten die Kommunen einen großen Beitrag zur Wohnberatung. 


\section{»Instrumente und Instrumenten-Alternativen« in Hessen}

Der hessische Policy-Mix zum barrierefreien bzw. -reduzierten Wohnraum orientiert sich zwar an der ARGEBAU-Musterbauordnung und dem KfW-Programm »Altersgerecht Umbauen«, ist aber insgesamt durch landeseigene Schwerpunktsetzungen geprägt. Dafür spricht die 20-Prozent-Regelung zum barrierefreien Bauen in der Bauordnung, die ausdifferenzierte Förderlandschaft der WIBank sowie die Hessische Fachstelle für Barrierefreiheit. Die staatliche Bereitstellung von barrierefreiem bzw. -reduziertem Wohnraum muss in Hessen bislang als potentielle, wenig genutzte Instrumenten-Alternative gelten, wohingegen die private Wohnungs- und Bauwirtschaft dieses Segment teilweise bereits für sich entdeckt hat. Diese wirtschaftliche Selbstregelung konzentriert sich indessen stärker auf das hochpreisige Segment und einzelne, unter dem Stichwort »Komfort « zu vermarktende Bestandteile der Barrierefreiheit. Ergänzend zu den landespolitischen Maßnahmen steuern einzelne Kommunen zudem über eigene Beratungsangebote und Förderprogramme, wohingegen die regulative Bauleitplanung und Konzeptvergabe bislang wenig in diesem wohnungspolitischen Teilbereich genutzt werden.

\subsubsection{Problemstrukturen}

Die Problemstrukturen zum barrierefreien bzw. -reduzierten Wohnraum in Hessen werden im Folgenden in drei Aspekte unterteilt: Erstens die allgemeinen Strukturen der Wohnungsmärkte im Bundesland, zweitens verschiedene Zielkonflikte und drittens die Herausforderungen, die mit der politischen Steuerung eines Querschnittsthemas einhergehen.

Strukturen der Wohnungsmärkte in Hessen

Barrierefreier bzw. -reduzierter Wohnraum ist nicht losgelöst von der allgemeinen Situation auf den Wohnungsmärkten zu verstehen. Die hessischen Märkte lassen sich dabei vereinfacht in das Rhein-Main-Gebiet und das übrige Bundesland unterteilen, wobei aus den Interviews eine klare Problemfokussierung auf die Frage nach bezahlbarem Wohnraum im Rhein-Main-Gebiet hervorgeht (IP 12: 46ff.; IP 18: 28, 163; IP 48: 16ff., 63ff.). Der Regionalverband FrankfurtRheinMain umfasst 2,4 Millionen der insgesamt knapp 6,3 Millionen hessischen Einwohner*innen und hatte allein von 2012 bis 2017 einen Bevölkerungszuwachs von 6,2 Prozent zu verzeichnen (Regionalverband FrankfurtRheinMain 2019: 4f., vgl. Abbildung 28).

Auch Indikatoren wie die Bevölkerungsdichte - etwa: Frankfurt a.M.:3.078 Einwohner*innen je km² im Vergleich zu 298 in Gesamthessen - und das Durchschnittsalter etwa: Frankfurt a.M.: 40,8 Jahre im Vergleich zu 43,8 Jahren in Gesamthessen - verdeutlichen die soziostrukturellen Besonderheiten des Rhein-Main-Gebiets (Hessisches Statistisches Landesamt 2020: 41; Hessisches Statistisches Landesamt 2019, vgl. auch Tabelle 6).

Die wohnungspolitische Schwerpunktsetzung auf das Rhein-Main-Gebiet vernachlässigt indessen die Situation auf den Wohnungsmärkten abseits der Ballungszentren: Teile Mittel- und Nordhessens, aber auch der ganz südliche Teil des Bundeslandes, ste- 
Abbildung 28: Metropolregion und Regionalverband FrankfurtRheinMain



(Quelle: Regionalverband FrankfurtRheinMain 2019: 5)

hen vor den typischen demografischen Herausforderungen des ländlichen Raums, womit veränderte Wohnraumbedarfe einhergehen (IP 12: 49ff.; IP 14: 4, 50; IP 50: 6). Zwar artikulieren verschiedene Interviewpartner*innen einen Bedarf nach einer regional differenzierten politischen Steuerung (IP 19: 52ff.; IP 48: 20ff.), allerdings spiegelt die politische Diskussion in Hessen exemplarisch die bereits im Forschungsstand aufgearbeitete Dominanz der Fragen nach bezahlbarem Wohnraum und Wohnraumknappheit wider (vgl. Kapitel 3.2). In diesem Kontext liegt der Fokus auf der Quantität von Wohnraum, sodass für qualitative Zusatzbedarfe wie das barrierefreie bzw. -reduzierte Wohnen wenig Raum bleibt (IP 7: 10ff.; IP 13: 61; IP 18: 87; IP 47: 22; IP 50: 2; IP 54: 81). Eine stärker kundenorientierte Ausrichtung der Wohnungs- und Bauwirtschaft sei angesichts der aktuellen Nachfrage nicht wahrscheinlich: »[L]etztendlich werden die Woh- 
nungen auch verkauft, ob die jetzt 4.000 oder 6.000€ pro Quadratmeter kosten. [...] Und das ist das größte Problem. Nämlich, aus dem ganzen Markt-egal, ob er jetzt barrierefrei sein soll oder nicht-diesen Spekulationswahn rausnehmen (IP 19: 51).

Weiterhin erschwert die heterogene Eigentümerstruktur auf den hessischen Wohnungsmärkten eine politische Steuerung. Neben vielen Selbstnutzer*innen ist nämlich auch der Mietwohnmarkt kleinteilig organisiert, bestehend aus kommunalen, genossenschaftlichen und privaten Wohnungsunternehmen sowie einer Vielzahl an privaten Kleinvermieter*innen (IP 18: 38; IP 50: 20ff.; vgl. auch Kapitel 5.2.1).

Dazu kommen die langfristigen und unsicheren Wirkungen von wohnungspolitischen und wohnungswirtschaftlichen Entscheidungen (IP 9:30; IP 50:2). Interessant ist in diesem Kontext eine Schwerpunktverschiebung in der politischen Diskussion. Dominiert die Bezahlbarkeit seit etwa Mitte der 2010er Jahre die Wohnungspolitik, wurde sich zuvor durchaus intensiv mit dem demografischen Wandel beschäftigt. Neben einer Enquetekommission zum demografischen Wandel und einer interministeriellen Arbeitsgruppe »Demografie « wurden in den Kommunen Demografie-Dialoge und -Preise initiiert. Unter breiter gesellschaftlicher Beteiligung entwickelte sich zudem eine seniorenpolitische Initiative. All diese senioren- und demografiepolitischen Aktivitäten haben "altersgerechten « Wohnraum dezidiert mitgedacht (Hessischer Landtag 2007: 3, 93ff.; Hessische Staatskanzlei 2013: 3f., 60ff.; Hessischer Landtag 2015a). Die hessischen Demografie-Berichte zeigen, wie sich die Beschäftigung mit diesem Thema über die Zeit verändert hat. So forderte der dritte Bericht im Jahr 2013 noch »[a]ngesichts der demografischen Herausforderungen [...] eine strategische Vernetzung der verschiedenen Politikbereiche« (Hessische Staatskanzlei 2013: 4). Der vierte Demografie-Bericht aus dem Jahr 2016 wiederum erklärt direkt im Vorwort »Hessens Bevölkerung wächst« (Hessische Staatskanzlei 2016: 3). Die Frage des Wohnens wird zunächst über die Bezahlbarkeit geführt, um dann bezogen auf die Alterung der Bevölkerung dem Handlungsfeld »Regionale Infrastruktur/Regionalentwicklung« zugeordnet zu werden (Hessische Staatskanzlei 2016: 12, 23). Hier zeigt sich die Dynamik von Problemstrukturen und damit auch, wie sehr die Bezahlbarkeit die Herausforderungen des demografischen Wandels in der wohnungspolitischen Diskussion abgelöst hat.

Zielkonflikte zum barrierefreien bzw. -reduzierten Wohnraum

Neben den Strukturen der hessischen Wohnungsmärkte prägen Spannungsverhältnisse $\mathrm{zu}$ anderen wohnungspolitischen oder wohnungswirtschaftlichen Interessen den barrierefreien bzw. -reduzierten Wohnraum. Diese werden von unterschiedlichen Akteuren unterschiedlich stark gewertet, was die Subjektivität der Problemstrukturen verdeutlicht. Zuerst ist der vielfach unterstellte Zielkonflikt zwischen Bezahlbarkeit und Barrierefreiheit bzw. -reduzierung zu diskutieren. Weitere wohnungsbauliche Interessen, die im Konflikt mit dem Untersuchungsgegenstand stehen können, werden danach ebenso untersucht wie die Frage nach unterschiedlichen Nutzergruppen mit je spezifischen Wohnraumbedarfen. Abschließend interessiert, inwieweit sich Barrierefreiheit nach DIN 18040-2 und eine eher »bedarfsgerechte« individuelle Wohnraumgestaltung im Wege stehen könnten. 
Bezahlbarkeit versus Barrierefreiheit?

Die Wohnungs- und Bauwirtschaft führt für den Neubau höhere Kosten als Argument gegen Barrierefreiheit ins Feld (IP 8: 73; IP 48: 48, 68; IP 51: 42; IP 52: 6) und auch ein Akteur aus dem für Bauen zuständigen Wirtschaftsministerium erklärt: »[U]nser Hauptfokus ist die Herstellung von bezahlbarem Wohnraum. Und barrierefreien Wohnraum oder rollstuhlgerechten Wohnraum herzustellen [...] konterkariert das ja eigentlich in gewisser Weise, weil das teurerist (IP 57: 13). Andersherum weisen nicht nur Behindertenverbände auf die Relevanz einer klugen Planung hin, sondern auch verschiedene kommunale Akteure und landespolitische Gesprächspartner*innen erklären, dass die entstehenden Mehrkosten durch flexiblere Grundrisse und eine Standardisierung von barrierefreien Modulen gering seien (IP 18: 106; IP 20: 26; IP 46: 61ff.; IP 47: 26; IP 49: 39; IP 50: 8, 26; IP 52: 52ff.; IP 53: 7; IP 54: 15; IP 55:35). Preissteigerungen in den Ballungsregionen seien zwar generell ein Problem, das aber habe "nicht zwangsläufig was damit zu tun, ob barrierefrei gebaut wird oder nicht « (IP 55: 35, vgl. auch IP 19: 18). Während für die Angebotsseite von Wohnraum die angespannten Wohnungsmärkte also ein Argument gegen zusätzliche barrierefreie Anforderungen sind, fragt ein Interessenvertreter von Menschen mit Behinderungen genau umgekehrt (IP 46: 61ff.): »[W]ann, wenn nicht zu dieser Hochpreisphase der Wohnungen, wann sollte man Barrierefreiheit rechtfertigen können?«

$\mathrm{Zu}$ einigen Mehrkosten besteht aber tatsächlich ein breiterer Konsens: Wohnungen für Rollstuhlfahrer*innen bedürften häufig größerer Grundflächen und seien damit teurer (IP 46: 85; IP 48:48, 68). Auch beim schwellenlosen Zugang zum Freisitz räumt eine Gesprächspartnerin, die ansonsten die kluge Planung hervorhebt, eventuelle Mehrkosten ein (IP 52: 95). Am konkretesten wird die Diskussion bei den Installations- und Wartungskosten von Aufzügen (IP 49: 29). Diesbezüglich relativiert der wohnungspolitische Sprecher der FDP allerdings: »Wann entsteht bitte schön heute noch ein Neubaumehrstöckig, mit mehr als drei Etagen -, wo kein Aufzug drin ist? [...] Und das jetzt der Barrierefreiheit anzulasten, finde ich einfach ganz schön unfair« (IP 50: 8).

Der Bestandsumbau wird hingegen deutlich weniger in den hessischen Interviews thematisiert - hier zeigt sich die Relevanz vom Neubau insbesondere im Rhein-MainGebiet. Für barrierereduzierende Maßnahmen gilt zunächst einhellig, dass eine nachträgliche Änderung umständlicher sei als eine direkte barrierefreie Planung (IP 18: 15; IP 47: 26). Eine Wohnberaterin erklärt jedoch, in der ohnehin notwendigen Sanierung ganzer Wohngebäude würden sich diese Mehrkosten in Grenzen halten: »[W]enn das strangweise saniert wird [...], das sei nicht so viel teurer als nicht barrierefrei« (IP 18: 106). Und andere Gesprächspartner*innen weisen darauf hin, dass wie schon im Neubau nicht die Barrierereduzierung der größte Kostentreiber sei, sondern die allgemeine Modernisierungsumlage in Verbindung mit vorher langjährigen, gebundenen Mietpreisen (IP 12: 49ff.; IP 55: 35ff.).

Zielkonflikte zu anderen wohnungsbaulichen Interessen

In der Bezahlbarkeits-Debatte der hessischen Wohnungspolitik haben es zusätzliche Interessen generell schwer und resultieren in einer Vielzahl an miteinander konkurrierenden Belangen. So könnten sich energetische Vorgaben stärker durchsetzen, was den verbleibenden Handlungsspielraum für barrierefreien bzw. -reduzierten Wohn- 
raum weiter verengt (IP 18: 120; IP 54: 19). Zudem verhinderten die schweren Brandschutztüren durch vielfach fehlende automatische Türöffnungen eine barrierefreie $\mathrm{Zu-}$ gänglichkeit (IP 50: 34ff.; IP 54: 17). Und für den politischen Diskurs zur Bauordnung ist die sogenannte Flachdachrichtlinie zu nennen, welche die Türübergänge von Freisitzen zur inneren Wohnung regelt und durch entsprechende Schwellen Wassereintritt verhindern soll (IP 19: 3; IP 46: 21ff.; IP 48: 54). Hier stehen zwei DIN-Normen im Widerspruch zueinander, was zu politisch kaum auflösbaren Konflikten führt (vgl. auch Kapitel 7.2.5).

Insgesamt ist es nicht die Barrierefreiheit allein, die von einigen Akteuren als Kostentreiberin im Wohnungsbau wahrgenommen wird. Vielmehr geht es um die Entwicklung der letzten Jahre oder Jahrzehnte, in der unterschiedlichste Forderungen an die Wohnungspolitik herangetragen worden sind, die in ihrer Summe Kostensteigerungen hervorrufen oder das Bauen verkomplizieren (IP 18: 81; IP 48: 20ff.). Eine fachliche Differenzierung dazu, was tatsächlich Mehrkosten verursacht, in welcher Höhe diese gerechtfertigt sind und was durch eine kluge Planung unproblematisch integriert werden kann, findet sich in den politischen Prozesse in Hessen nur zum Teil.

\section{Zielkonflikte durch unterschiedliche Nutzergruppen}

Ein weiterer Zielkonflikt zum barrierefreien bzw. -reduzierten Wohnraum besteht darin, dass sich die unterschiedlichen Nutzer*innen teils in ihren Bedarfen widersprechen und dadurch eine standardisierte politische Steuerung erschwert wird (IP 14: 46). So bräuchten blinde und sehbehinderte Menschen zur besseren Orientierung häufig kleinere Raumzuschnitte, gehbeeinträchtige Menschen hingegen größere Bewegungsflächen (IP 54: 77). Besonders evident wird diese Problemstruktur beim rollstuhlgerechten Wohnraum - bereits Elektrorollstühle und manuelle Kassenmodelle führen zu unterschiedlichen Spielräumen der Nutzer*innen und stehen noch dazu durch die benötigte Schwellenlosigkeit und größeren Bewegungsflächen im Zielkonflikt zu den Bedarfen von sehbeeinträchtigten Menschen (IP 54: 7, 61).

Generell erscheint vor allem der rollstuhlgerechte Wohnraum politisch schwer steuerbar, da es hier besonders schwierig sei, Angebot und Nachfrage zusammenzubringen (IP 12: 114; IP 15: 23; IP 53: 7). In der Folge würden rollstuhlgerechte Wohnungen in Hessen kaum gebaut - was die Wohnungssuche für die einzelnen Nutzer*innen wiederum erschwert (IP 18: 28f.; IP 52: 16). Von daher ist sogar ein gegenseitiges SichAusspielen von barrierefreien Wohnungen mit und ohne R-Anforderung zu erkennen: "[M]an braucht nicht jede Wohnung rollstuhlgerecht [...]. Und das würde sicherlich nicht zur Verteuerung führen, würde aber vielen Leuten nutzen « (IP 20: 30, vgl. Kapitel 7.2.5).

Letztlich gelten auch ältere Menschen als Nutzergruppe von barrierefreiem bzw. -reduziertem Wohnraum. Hier wird ein präventives Handeln durch die Unsicherheit gehemmt, wie stark sich potentielle oder bereits vorhandene Einschränkungen mit zunehmendem Alter noch verschlechtern. Vielfach beschäftigen sich ältere Menschen folglich erst im akuten Bedarfsfall mit der Anpassung ihres Wohnraums (IP 13: 7ff.; IP 47: 34; IP 50: 32; IP 55: 47ff.). Bei selbstnutzenden Eigentümer"innen stünden zudem Straßenausbaubeiträge, Grundsteuern oder verpflichtende energetische Nachrüstungen weiter oben auf der Prioritätenliste (IP 13: 47; IP 18: 113f.; IP 55: 15). Meist ist im 
Krankheitsfall auch ein Verbleiben in den eigenen, vertrauten Wänden gewünscht (IP 15: 23ff.). Besteht die Bereitschaft zu einem Umzug, müsste der neue Wohnraum zentrumsnah sein oder sich im selben Stadtteil wie bislang befinden, um die vertraute Umgebung nicht verlassen zu müssen. Hier verstärken sich die einzelnen Aspekte der Problemstrukturen gegenseitig, da die aktuellen Miet- und Kaufpreise von kleineren Wohnungen durch die Preissteigerungen teurer sind als die bisher größeren Wohnflächen (IP 49: 3ff.; IP 55: 43ff.).

Diese Herausforderung leitet über zur Frage des verfügbaren Einkommens. So bestünden barrierefreie Ausstattungen - wie gezeigt - durchaus in sogenannten »LuxusApartments«, vielfach verbunden mit zusätzlichen Betreuungs- oder Serviceleistungen (IP 20: 50, vgl. auch IP 14: 4; IP 46: 85; IP 47: 22). Demgegenüber hätten es nicht nur Empfänger*innen sozialstaatlicher Transferleistungen, sondern im Rhein-Main-Gebiet auch die mittleren Einkommen schwer, geeigneten Wohnraum zu finden (IP 12: 70; IP 14: 65ff.). Spezifisch für den sozialen Wohnungsbau verschärfe sich die Situation durch eine unzulängliche Planung: »Das Problem der Barrierefreiheit kommt nur dort zustande, wo die schlechten Planer tätig sind. Nämlich bei den günstigen Wohnungen« (IP 46: 85).

Abschließend spricht sich insbesondere die Nachfrageseite nach Wohnraum ohnehin gegen eine Fokussierung auf einzelne Nutzergruppen aus: Würde Barrierefreiheit als Gewinn für alle verstanden, könnten sich gewisse Basisstandards durchsetzen und zur Normalität werden (IP 13: 57; IP 15: 93; IP 20: 26; IP 47: 24; IP 50: 34ff.; IP 54: 19). Diese Forderung leitet allerdings direkt über zu der Frage, wie ein solcher Basisstandard aussehen könnte.

Barrierefreiheit oder Barrierereduzierung?

Der letzte Zielkonflikt beschäftigt sich mit unterschiedlichen Ausstattungskriterien, wozu es ein breites Spektrum vom individuellen Umbau im Bestand über von der Wohnungs- und Bauwirtschaft selbst definierte »barrierearme« Standards bis hin zur DIN 18040-2 gibt (IP 8: 43; IP 46: 5; IP 54: 75). Da eine politische Steuerung zwangsweise Standards definieren muss, stellt sich die Frage, inwiefern ein »schwächerer« Standard als Argument gegen rigidere Vorgaben ausgespielt wird. Während die Angebotsseite von Wohnraum sich für bedarfsgerechte oder eigens definierte bauliche Lösungen ausspricht, fordern Behindertenverbände allgemeingültige verbindliche Standards (vgl. Kapitel 7.2.5). Noch schwieriger wird diese Diskussion durch die Idee der Schutzziele, nach der die Ziele der DIN 18040-2 »auch auf andere Weise als in der Norm festgelegt erfüllt werden« können (Rau 2012: 28, vgl. Kapitel 2.2). Das gewährleistet mehr Flexibilität in der Planung, eröffnet aber zugleich Interpretationsspielräume. Dazu erklärt eine Akteurin aus der kommunalen Wohnraumförderung: "Das ist für mich ein ganz, ganz wichtiger Satz. Weil ich in Teilen meine, dass die Ausführungen, die dann hinten in der DIN zeichnerisch drin sind, halt oft nicht so umgesetzt werden können und sie qualitativ auch nicht unbedingt so toll sind« (IP 52: 18ff.). Es ist also ganz wesentlich, welche qualitativen Kriterien politische Entscheider*innen in welcher Starrheit oder Flexibilität in der politischen Steuerung festschreiben. 
Politische Steuerung von Querschnittsaufgaben

Nach den Strukturen auf den Wohnungsmärkten und den Zielkonflikten wird abschließend die Querschnittsthematik als dritter Aspekt der Problemstruktur erörtert. So verweisen verschiedenste Interviewpartner*innen auf die Relevanz einer wohnortnahen Infrastruktur, insbesondere bezogen auf gesundheitliche Dienstleistungen und Mobilitätsangebote (IP 20: 12; IP 18: 87ff.; IP 46: 85ff.; IP 52: 66; IP 54: 45; IP 55: 41). Nur eine ganzheitliche Betrachtung könne die Nachfrage nach barrierefreiem bzw. -reduziertem Wohnraum angemessen adressieren. Dabei erklärt ein Interviewpartner, dass

»Barrierefreiheit ja nicht dadurch entsteht, dass ich irgendwo eine rollstuhlgerechte Wohnung mache, sondern ich muss mich ja auch fragen: > Wo komme ich von der Wohnung aus hin und kann ich mich in dieser Wohnung auch versorgen? Das ist ja erst Barrierefreiheit« (IP 46: 85ff.).

Diese Themen können lediglich im Rahmen einer breiteren Quartiers- oder Stadtentwicklung gesteuert werden und stoßen damit an politikfeldübergreifende Grenzen.

Ähnliches gilt für soziale Aspekte des gemeinschaftlichen Wohnens. Auch hier soll durch Quartiersansätze oder Mehrgenerationenwohnen eine umfassendere Antwort auf Fragen des zukünftigen Wohnens gefunden werden. Während barrierefreier bzw. -reduzierter Wohnraum einen Teilaspekt solcher Projekte abdecken kann, werden umfassendere Zielvorstellungen für ein stärkeres Miteinander und damit auch gegen Vereinsamung im Alter formuliert (IP 15: 9ff.; IP 19: 15ff.; IP 20: 55ff.; IP 46: 81). Auch hier zeigt sich die für einen kohärenten Policy-Mix notwendige Beteiligung verschiedenster Politikfelder, auf die unter den institutionellen Regelungen noch stärker eingegangen wird (vgl. Kapitel 7.2.4).

\section{»Problemstrukturen« in Hessen}

Die Problemstrukturen zum barrierefreien bzw. -reduzierten Wohnraum werden in Hessen durch den wohnungspolitischen Schwerpunkt auf die Wohnraumknappheit und -verteuerung im Rhein-Main-Cebiet geprägt. Entsprechend deutlich artikuliert insbesondere die Wohnungs- und Bauwirtschaft einen Zielkonflikt zwischen bezahlbarem und entsprechend ausgestattetem Wohnraum. Erschwerend hinzu kommt, dass unterschiedliche Nutzergruppen - bspw. Menschen mit einer Seh-oder einer Gehbeeinträchtigung - unterschiedliche barrierefreie Ausstattungen benötigen und außerdem über unterschiedliche finanzielle Handlungsspielräume verfügen. Schließlich sehen viele Interviewpartner*innen barrierefreien bzw. -reduzierten Wohnraum nur im Zusammenspiel mit einer integrierten Stadtentwicklung und der Berücksichtigung von sozialen Belangen des Bauens - neben der baulichen Barrierefreiheit - als kohärent adressiert.

\subsubsection{Situative Aspekte}

Neben Problemstrukturen und den Instrumenten sowie Instrumenten-Alternativen beeinflussen externe situative Aspekte politische Prozesse (vgl. Kapitel 4.4). Zum barrierefreien bzw. -reduzierten Wohnraum in Hessen lassen sich im Bauordnungsrecht schwache, in der Wohnraumförderung hingegen stärkere situative Aspekte ausmachen. 
Die Bauordnung wird in Hessen turnusmäßig novelliert, sodass es zusätzlicher externer Effekte nicht unbedingt bedarf. Eine Interviewpartnerin erklärt: »Jetzt stand halt die Novellierung der Bauordnung an. Also befasse ich mich turnusmäßig dann sehr stark damit und dann fällt es halt wieder für die nächsten drei, dreieinhalb Jahre zurück« (IP 14: 6). Hier können Veränderungsinteressen für eine stärkere Verankerung von Barrierefreiheit also ein sich ohnehin durch die routinierte Überarbeitung eröffnendes Möglichkeitsfenster nutzen. Zwar verweist ein anderer Gesprächspartner auf eine EU-Richtlinie zur Bauprodukte-Verordnung, wofür die bauordnungsrechtliche Harmonisierung geprüft werden musste (IP 9: 38). Diese europäische Richtlinie kann aber eher als Verstärkerin denn als Auslöserin zur ohnehin anstehenden Bauordnungsnovellierung verstanden werden. Zudem zeigen die Novellierung des Jahres 2018, dass sich öffnende Möglichkeitsfenster nicht zwangsweise im Sinne der Veränderungsinteressen für eine stärkere Verankerung der Barrierefreiheit genutzt werden können (vgl. Kapitel 7.2.5.2).

Für die Wohnraumförderung ist die sogenannte Flüchtlingskrise seit 2015 ein situativer Aspekt, wobei diese nicht eindeutig als förderlich oder hemmend auf die politische Steuerung zum barrierefreien bzw. -reduzierten Wohnraum wirkt. Einerseits legt die Landesregierung in Reaktion auf die starken Zuzugszahlen ein Kommunalinvestitionsprogramm über 230 Millionen Euro auf, darin enthalten ist ein spezifischer Programmbestandteil »Wohnraum« (IP 57: 22ff.). Aber »bis das lief [...], da war die Flüchtlingsproblematik nicht mehr so tragisch, jedenfalls nicht binnentechnisch, außen natürlich weiterhin. Und von daher ist das dann eher so in die normale Klientel übergegangen « (IP 17: 77). Im Rahmen dieser zusätzlichen Wohnraumförderung wird auch Barrierefreiheit unterstützt. Andererseits beschreiben verschiedene Interviewpartner*innen den erhöhten außereuropäischen Zuzug eher als Unmöglichkeitsfenster für die Beschäftigung mit barrierefreiem bzw. -reduziertem Wohnraum. So wurde dadurch nicht nur die politische Aufmerksamkeit insgesamt gebunden, sondern auch die bereits bestehende Wohnraumknappheit in den Ballungszentren weiter verschärft. Dies verstärkte die Fokussierung auf bezahlbaren und schnellen Wohnungsbau und drängte Zusatzbedarfe weiter in den Hintergrund (IP 14: 6; IP 50: 2).

\section{"Situative Aspekte« in Hessen}

In den untersuchten politischen Prozessen zum barrierefreien bzw. -reduzierten Wohnraum eröffnen situative Aspekte eher keine Möglichkeitsfenster für Veränderungsinteressen hin zu einer stärkeren Verankerung von Barrierefreiheit. Der außereuropäische Zuzug seit 2015 wirkt hingegen als Unmöglichkeitsfenster, indem es die politische Aufmerksamkeit in Hessen weiter auf die Frage nach bezahlbarem und schnellem Wohnungsbau lenkt.

\subsubsection{Institutionen}

Der vierte der fünf AEP-Erklärungsfaktoren fragt nach der Rolle politischer Institutionen in den politischen Prozessen zum barrierefreien bzw. -reduzierten Wohnraum. Auf theoretischer Ebene wurde eine Unterteilung in inklusionspolitische Übereinkommen, 
Institutionen im Bundesland sowie in die Regelungen im föderalen Mehrebenensystem vorgenommen (vgl. Kapitel 4.5).

Inklusionspolitische Abkommen und Konventionen

Wichtige inklusionspolitische Institutionen sind der Hessische Aktionsplan zur Umsetzung der UN-Behindertenrechtskonvention aus dem Jahr 2012 sowie das zuletzt 2019 überarbeitete Hessische Behinderten-Gleichstellungsgesetz (HessBGG). Das HessBGG befasst sich zwar vor allem mit dem öffentlichen Raum, formuliert aber in $\$ 7$ auch Ziele für ein selbstbestimmtes Wohnen (Bürgerservice Hessenrecht 2019). Bei der letzten Novellierung kritisierten sowohl Behindertenverbände als auch SPD und DIE LINKE die formulierte Soll-Regelung statt einer verbindlichen Ist-Regelung zum Wunschund Wahlrecht der selbstbestimmten Wohnform (Hessischer Landtag 2018d; Hessischer Landtag 2018k: 42; Hessischer Landtag 20181: 3, 58). Die schwarz-grüne Landesregierung verblieb bei der weniger bindenden Soll-Regelung. Dennoch hat das HessBGG Auswirkungen auf die politischen Prozesse zum barrierefreien bzw. -reduzierten Wohnraum, weil die Veränderungsinteressen diese normative Zielvorgabe als Argument nutzen können. Dies gilt exemplarisch für das Kriterium der »Auffindbarkeit« in $\$ 3$ (1) HessBGG und darauffolgend in der Hessischen Bauordnung (Bürgerservice Hessenrecht 2019; IP 12: 4, vgl. Kapitel 7.2.5).

Der Hessische Aktionsplan formuliert Ziele und Maßnahmen für einzelne Politikbereiche (HMSI 2012: 3). Zum barrierefreien Wohnen ist ein Förderprogramm zum behindertengerechten Umbau festgeschrieben (vgl. Kapitel 7.2.1), außerdem eine Stärkung von ambulanten Wohnformen und eine Bestands- sowie Bedarfserhebung von Wohnangeboten für Menschen mit Behinderungen (ebenda: 54f.). Übergeordnet, aber mit Bezug zum Bauen und Wohnen, wird Barrierefreiheit als Ausbildungsinhalt für Architekt*innen, Ingenieur*innen und Handwerksberufe gefordert sowie die Einrichtung einer zentralen Fachstelle für Barrierefreiheit (ebenda: 48). Im Jahr 2016 hat der Aktionsplan zudem zur Einführung eines Normprüfleitfadens geführt, der verbindlich auf alle hessischen Gesetze und Verordnungen anzuwenden ist und ihre Konformität zu den Zielen der UN-BRK überprüft (HMSI 2012: 48; Hessischer Landtag 2016d: 2; HMSI 2016).

Im Folgenden ist $\mathrm{zu}$ zeigen, dass diese inklusionspolitischen Institutionen einerseits politischen Handlungsdruck in der Wohnungs- und Baupolitik erzeugen, andererseits aber verschiedene Herausforderungen beim Vereinbaren der unterschiedlichen Ressortinteressen bestehen.

Institutionen im Bundesland: Ministerieller Zuschnitt und Politikintegration

In Hessen sind die Ressortzuständigkeiten für barrierefreien bzw. -reduzierten Wohnraum seit 2019 zwischen den beiden grün geführten Wirtschafts- und Sozialministerien aufgeteilt. Im Ministerium für Wirtschaft, Energie, Verkehr und Wohnen mit Minister Al-Wazir an der Spitze ist die Abteilung VII für Bauen, Wohnen, Städtebau und Bundesfernstraßenprojekte zuständig. Darin beschäftigen sich die Referate 3 und 4 mit Baurecht sowie Bautechnik und bilden die Oberste Bauaufsicht. Die Referate 6 und 7 bearbeiten die Städtebau(-förderung) sowie Wohnungsbau und Wohnungsrecht (HM- 
WEVW 2020b). Im Ministerium für Soziales und Integration unter Minister Kai Klose liegen die Zuständigkeiten für Senior*innen (Abteilung II, Referat 5) sowie Menschen mit Behinderungen und die UN-Behindertenrechtskonvention (Abteilung IV, Referat 4) (HMSI 2020a). Da die untersuchten politischen Prozesse vor das Jahr 2019 zurückreichen, ist auch der Ressortzuschnitt der Legislaturperiode von 2014 bis 2019 relevant. Hier waren die Zuständigkeiten stärker verschachtelt: Das Wirtschaftsministerium unter Al-Wazir war bereits für das Bauordnungsrecht zuständig, wohingegen die Wohnraumförderung im ebenfalls grün geführten Umweltministerium von Ministerin Hinz lag. Die Zielgruppen der Senior*innen und Menschen mit Behinderungen wurden auch damals vom Sozialministerium verantwortet, allerdings geführt unter CDU-Minister Grüttner (Hessische Staatskanzlei 2019: 223; IP 57: 13).

Der Ressortlogik folgend werden Gesetzesvorhaben zunächst von den zuständigen Fachabteilungen ausgearbeitet und gehen nach einer ersten Besprechung der Regierungsfraktionen in die Ressortabstimmung (IP 19: 21; IP 53: 37). Diese Logik entspricht der klassischen negativen Koordination, nach der ein Ressort zuständig ist und im Rahmen seiner Handlungsspielräume agiert. Für Querschnittsthemen wiederum benennt ein oppositioneller wohnungsbaupolitischer Sprecher ein "gewisses Kompetenzgerangel [...], wenn es wirklich um Bauordnungen geht, um die Normensetzung, wird sich das Bauministerium [...] nicht reinreden lassen « (IP 50: 13f., vgl. auch IP 54: 23ff.). Diese Einschätzung lässt sich für die Wohnraumförderung bestätigen, wozu ein ministerieller Ansprechpartner erklärt: »Unser Hauptfokus ist die Herstellung von bezahlbarem Wohnraum. [...] Und bei uns ist es auch nicht ordinäre Aufgabe, barrierefreien Wohnraum herzustellen « (IP 57: 13). Die Zuständigkeit für Barrierefreiheit wird indessen im Sozialressort verortet. Eine positive Koordination der Ressorts sei zwar offiziell angestrebt, vielfach aber nicht gegeben (IP 14: 54; IP 49: 29f.; IP 55: 59). Beispielhaft ausführen lässt sich dies ebenfalls an der Wohnraumförderung. Hierzu erklärt eine Interviewpartnerin aus der WIBank, dass das Sozialministerium mit dem Wohnungsbau keine Berührung habe. Überschneiden sich die Ressortzuständigkeiten bei einzelnen Projekten, »dann schieben sich die Ministerien die Verantwortung hin und her (lacht). Und, wir haben auch Seniorenwohnanlagen mit Pflegeteil, der Pflegeteil im Sozialministerium und der Wohnteil in Verantwortung vom Wohnungsbauministerium« (IP 17: 66ff.).

Die Interviews auf der kommunalen Ebene verstärken das Bild der voraussetzungsvollen Zusammenarbeit zwischen den Ressorts. Arbeitskreise zur ressortübergreifenden Zusammenarbeit seien aus inklusionspolitischer Perspektive vielfach unbefriedigend, da die Bereiche Planen, Bauen oder Wohnen sich teils nicht beteiligten (IP 18: 51ff., 126ff.; IP 51: 2ff.; IP 54:3). Die Versuche zur positiven Koordination brauchen einen langen Atem und versanden vielfach wieder (IP 54: 45). Als eine Institutionalisierung von barrierefreien Belangen werden deshalb Stabstellen eingerichtet oder Behindertenbeauftragte eingestellt. Diese sind meist im Sozialdezernat angesiedelt, womit die Zuschreibung zum Sozialressort bestehen bleibt (IP 18: 48, 78ff.; IP 51: 2ff.; IP 52: 66).

Zum Untersuchungszeitpunkt im Jahr 2019 finden sich in Hessen Bemühungen zu einer stärkeren Bündelung der inklusionspolitischen Belange, etwa zu Arbeitsmarktförderung, der UN-BRK und dem/der Behindertenbeauftragte*n. Dies geschieht durch eine Umsiedlung dieser bislang auf verschiedene Ministerien verteilten Zuständigkeiten in das Sozialministerium (IP 46: 100). Hier bleibt abzuwarten, inwieweit diese Bün- 
delung das Disability Mainstreaming stärkt oder aber zu einer noch deutlicheren sozialpolitischen Verankerung führt. Darüber hinaus schreibt der Koalitionsvertrag des Jahres 2019 erstmals die Funktion des/der Behindertenbeauftragten der Landesregierung als hauptamtliche Tätigkeit fest (Landesregierung Hessen 2019: 23). Der/die Amtsträger*in wird durch einen sogenannten Inklusionsbeirat, bestehend aus 32 Mitgliedern aus Ministerien sowie unterschiedlichsten Behindertenverbänden, beraten (Land Hessen 2014). Im weiteren Verlauf wird jedoch noch zu zeigen sein, dass die bisherige Behindertenbeauftragte in den untersuchten Prozessen nicht als aktiver Player auftrat (vgl. Kapitel 7.2.5). Das Wechselspiel zwischen institutioneller Zuständigkeit und der Tätigkeit individueller Akteure zeigt sich auch im Referat zur Umsetzung der UN-Behindertenrechtskonvention, das von Behindertenverbänden eher kritisch gesehen wird: »Und da gab es dann den Referatsleiter, der dann also in Vorträgen wortreich erzählt hat, was sie machen könnten und machen wollen. [Aber] ich behaupte, dass der bisherige Sozialminister [vor 2019, Anm. der Autorin] die Order aufgegeben hat: niedrighalten, kleinhalten, darf nichts kosten « (IP 8: 97ff., vgl. auch IP 46: 104).

Die vorherigen Ausführungen belegen eine Dynamik in Hessen, deren Ergebnisse erst noch abzuwarten sind. Neben der Institutionalisierung entsprechender Stellen finden sich weitere Anstrengungen der positiven Koordination in ressortübergreifenden Strategiepapieren. Wichtig sind dabei - wie vorab gezeigt - der Hessische Aktionsplan zur Umsetzung der UN-BRK sowie das HessBGG. Einschränkend handelt es sich bei einem Aktionsplan jedoch um kein verbindliches Gesetz, sondern um eine normative Leitlinie. Insofern basiert sein Erfolg wesentlich auf der konkreten Umsetzung, wozu eine Teilnehmerin aus entsprechenden Arbeitsgruppen erklärt: »[W]enn wir in diesen Sitzungen sind, [...] da sitzt natürlich immer jemand dabei vom Wirtschaftsministerium. Der letztendlich dann immer sagt: >Öt, das geht nicht « (IP 14: 70). Der Formulierung entsprechender Zielvorgaben muss also immer auch eine Umsetzung durch die jeweils zuständigen Ressorts folgen, die wiederum an ressortspezifischen, im Zielkonflikt mit Barrierefreiheit stehenden Interessen scheitern kann.

Institutionen im Mehrebenensystem: Up-Scaling, Down-Scaling, Through-Scaling Nicht nur die institutionellen Regelungen im Bundesland beeinflussen politische Prozesse, sondern auch das föderale Mehrebenensystem. Inwieweit bestehen hier Formen des Through-Scaling zwischen einzelnen Bundesländern? Und greift die Landesebene für ihre Politikgestaltung kommunale oder bundespolitische Initiativen auf (vgl. Kapitel 4.5.3)?

Durch die Landeszuständigkeit im Bauordnungsrecht und in der sozialen Wohnraumförderung ist es naheliegend, dass die Bundesländer sich gegenseitig konsultieren. Auf formalisiertem Wege geschieht dies über ministerielle Fachkommissionen oder Gremien der Förderbanken, wobei barrierefreier bzw. -reduzierter Wohnraum allerdings »jetzt nicht so das zentrale Thema« sei (IP 10: 22, vgl. auch IP 17: 87ff.). Es würde zwar durchaus geschaut, was andere Länder für Regelungen formulierten, die hessische Politikgestaltung richtet sich indessen stärker an den regionalen Strukturen und Pfadabhängigkeiten im eigenen Land aus. Für die Wohnraumförderung erklärt ein Ansprechpartner aus dem Wirtschaftsministerium: »[W]enn ein System sich da in einem Bun- 
desland etabliert hat, hält jeder an seinem Prozedere meistens auch fest (IP 57: 19ff., vgl. auch IP 8: 96f.; IP 50: 8).

Ergänzend bescheinigt eine wohnungsbaupolitische Sprecherin, dass der Input zu neuen Policy-Ideen eher über die landesinterne Verbandslandschaft denn durch landesübergreifenden Austausch des politisch-administrativen Systems erfolge (IP 19: 33f.). In diesem Kontext sind die Verbandsstrukturen selbst wichtig, wie etwa der VdK HessenThüringen, der VdK Südwest für Hessen und Rheinland-Pfalz sowie der BFW Landesverband Hessen/Rheinland-Pfalz/Saarland belegen. Diese Akteure berufen sich in ihrer Argumentation durchaus auf Regelungen aus anderen Bundesländern (vgl. Kapitel 7.2.5). Und für konkrete Gesetzesvorhaben bestätigt eine wohnungsbaupolitische Sprecherin: »Also, ich schaue ab (lacht). [...] Wir sind ja auch in der Opposition, also [...] eigene Gesetzentwürfe schreiben ist so eine Geschichte. [...] Da ist es für mich eigentlich einfacher [...]: Wo, in welchem Bundesland, funktioniert dies oder das besser? (IP 49: 49). Hier zeigt sich eine Querverbindung zu den Ressourcen, wobei Oppositionsfraktionen im Gegensatz zu Regierungen nicht auf einen ministeriellen Unterbau zurückgreifen können (vgl. Kapitel 4.6.2). Stärker als formalisierte Austauschformate wirkt hier aber die informelle Koordination über eigene Recherchen oder Kontakte.

Auch vertikale Prozesse des Up- und Down-Scaling lassen sich aus dem empirischen Material nur begrenzt herausarbeiten. Zwar zeigen die Instrumenten-Alternativen, dass den Kommunen verschiedenste Handlungsspielräume beim barrierefreien bzw. -reduzierten Wohnraum zugesprochen wurden (vgl. Kapitel 7.2.1), hier sind die Zuständigkeiten zwischen Land und Kommunen aber klar verteilt, sodass kommunale Aktivitäten keinen Einfluss auf die landespolitische Politikformulierung haben. Das einzige vertikale Down-Scaling von der Bundesebene auf die hessische Ebene besteht in der Wohnraumförderung durch die Weiterleitung des KfW-Programms »Altersgerecht Umbauen « - dieses Programm ist allerdings nur ein Bestandteil des insgesamt ausdifferenzierten hessischen Förderinstrumentariums (vgl. ebenfalls Kapitel 7.2.1).

\section{»Institutionen« in Hessen}

Der Hessische Aktionsplan zur Umsetzung der UN-BRK sowie das Hessische Behindertengleichstellungsgesetz dienen den Veränderungsinteressen als Argumentationsgrundlage für eine stärkere politische Verankerung der Barrierefreiheit. Zugleich sind für die Umsetzung der darin festgeschriebenen Maßnahmen wiederum die einzelnen Ressorts zuständig. Für den barrierefreien bzw. -reduzierten Wohnraum ist dies das Wirtschafts- bzw. bis 2019 zusätzlich das Umweltministerium, wobei trotz verschiedenen Versuchen der Politikintegration (interministerielle Arbeitskreise, Funktion des/der Behindertenbeauftragten) die Ressortlogik dominiert. Die Zuständigkeit für »Barrierefreiheit« ist zuvorderst dem Sozialministerium zugeschrieben, Zielkonflikte etwa zum bezahlbaren Wohnraum werden klar formuliert. Dabei richtet sich die hessische Wohnungspolitik vor allem an den bestehenden Strukturen im eigenen Land aus, während institutionalisierte Formate im föderalen Mehrebenensystem kaum konsultiert werden. Bei der Überarbeitung konkreter Richtlinien oder Gesetzesvorhaben sind es eher infor- 
melle Kanäle des politisch-administrativen Systems oder über die Landesgrenzen hinaus tätige Verbände, die ein Through-Scaling aus anderen Bundesländern anstoßen.

\subsubsection{Akteure und ihre Handlungen}

Akteure und ihre Handlungen bilden den letzten Erklärungsfaktor der Analyse, dabei schreibt der AEP als handlungsorientierte Heuristik den Akteuren eine wesentliche Rolle in den politischen Prozessen zu (vgl. Kapitel 4.6). Im Folgenden werden für den barrierefreien bzw. -reduzierten Wohnraum außerparlamentarische Interessen, parteipolitische Akteure und die Ministerialverwaltung analysiert. Dafür erfolgt zunächst eine Erörterung, wie sich diese einzelnen Akteursgruppen in Hessen zusammensetzen. Daraufhin stehen die konkreten Prozesse zum Bauordnungsrecht, zur Wohnraumförderung und $\mathrm{zu}$ informationellen Maßnahmen im Fokus. Welche Interessen verfolgen die Akteure und welche Ressourcen sowie Strategien nutzen sie zur Durchsetzung dieser Interessen?

\subsubsection{Strukturierung der Akteure und ihre übergeordneten Interessen}

Um zu verstehen, wie sich die drei Akteursgruppen zusammensetzen, werden diese zunächst konkretisiert. Welche außerparlamentarischen Interessen, parteipolitischen Akteure und Akteure der Ministerialverwaltung sind beteiligt an den politischen Prozessen zum barrierefreien bzw. -reduzierten Wohnraum in Hessen? Und inwiefern lassen sich übergeordnete Interessen zu diesem Untersuchungsgegenstand herausarbeiten?

\section{Außerparlamentarische Interessen}

Die außerparlamentarischen Interessen wurden in der theoretischen Vorarbeit in die Angebots- und Nachfrageseite nach Wohnraum unterteilt (vgl. Kapitel 4.6.1). Dabei setzt sich die Angebotsseite aus der Wohnungs- und Bauwirtschaft inklusive weiteren am Bau und Umbau beteiligten Akteuren zusammen. Zur gemeinsamen Interessenvertretung besteht eine Arbeitsgemeinschaft der Wohnungs- und Immobilienverbände (AWI-Hessen), in der sich unter anderem der Verband der Südwestdeutschen Wohnungswirtschaft (VdW) und der Landesverband freier Immobilien- und Wohnungsunternehmen Hessen/Rheinland-Pfalz/Saarland organisieren (vgl. IP 48: 12). Die breiteren Arbeitgeber- und Wirtschaftsverbände sind in der Vereinigung der hessischen Unternehmerverbände (VhU) gebündelt, wohingegen Architekt*innen, Ingenieur*innen und Handwerker"innen in Form von Kammern ihre Interessen vertreten (Schroeder/Geiger 2016: 188f.). Haus und Grund Hessen ist als Vertretung der privaten Vermieter*innen insbesondere in der Bauordnungsnovellierung aktiv. Insgesamt ist der Angebotsseite von Wohnraum ein wohnungswirtschaftliches Interesse zu unterstellen, wobei barrierefreier bzw. -reduzierter Wohnraum im Zielkonflikt mit anderen Interessen wie Kosten oder Vermietbarkeit stehen kann (vgl. Kapitel 7.2.2).

Die Nachfrageseite nach entsprechend ausgestattetem Wohnraum setzt sich für eine stärkere Verankerung von Barrierefreiheit in der Wohnungspolitik ein. In Hessen sind unterschiedliche Behindertenverbände dieser Nachfrageseite zuzuordnen, dazu 
auch größere Sozialverbände wie der VdK Hessen-Thüringen (IP 53: 24; IP 57: 3). Weniger involviert sind Vertretungen von Senior*innen:

»Die sind aber mehr so im Kultur- und Freizeitbereich tätig. [...] Also, was Bauen und Wohnen angeht [...]: Die halten sich da sehr, sehr zurück und sehen das wirklich eher so als Privatsache [...]. Also, sie möchten nicht als Gruppe wahrgenommen werden, die irgendwelche Defizite hat, sondern möchten eher wahrgenommen werden, so was in der Werbung gerade herumschwirrt, so diese Best Ager (IP 54: 53ff., vgl. auch IP 15: 32ff.; IP 20: 18; IP 50: 27ff.).

Auch Mieterschutzverbände sind in den politischen Prozessen zum barrierefreien bzw. -reduzierten Wohnraum keine aktiven Player (IP 20: 20).

Eine hessische Besonderheit ist die Allianz für Wohnen, die bereits als kooperatives Instrument eingeführt worden ist (vgl. Kapitel 7.2.1). Ihre Rolle als handelnder Akteur wird, sofern in den untersuchten politischen Prozessen relevant, ebenfalls diskutiert.

\section{Parteipolitik}

Parteipolitische Akteure werden über die Fraktionen im hessischen Landtag operationalisiert. Die 20. Wahlperiode in Hessen dauert von 2019 bis 2024 an und wird von einer schwarz-grünen Koalition unter CDU-Ministerpräsident Volker Bouffier geführt (Kabinett Bouffier III). Insgesamt besteht der Landtag aus 137 Abgeordneten, wobei auf die beiden Regierungsfraktionen CDU mit 40 Mitgliedern und Bündnis 90/Die Grünen mit 29 Mitgliedern die Mehrheit der Sitze entfällt. Ferner sind vier weitere Fraktionen im Landtag vertreten: SPD (29), AfD (18), FDP (11) und DIE LINKE (9). Dazu gibt es eine fraktionslose Abgeordnete (Hessischer Landtag 2019c: 7, 147). Die meisten der untersuchten politischen Prozesse reichen jedoch in die vorherige Legislaturperiode zurück. Von 2014 bis 2019 bestand der hessische Landtag aus fünf Fraktionen mit insgesamt 110 Abgeordneten: Gemeinsam am meisten Sitze hatten wiederum die Regierungsfraktionen CDU (47) und Bündnis 90/Die Grünen (14). Die mit Abstand stärkste Oppositionsfraktion war die SPD mit 37 Sitzen, gefolgt von DIE LINKE und FDP mit je sechs Sitzen (Hessische Staatskanzlei 2019: 223).

Über Wahlprogramme und Koalitionspapiere ist eine erste Annäherung an die inhaltlichen Interessen der Parteien möglich. Inwiefern bestehen beim barrierefreien bzw. -reduzierten Wohnraum parteipolitische Unterschiede? In der Landtagswahl 2018 ist »Wohnen« angesichts der angespannten Wohnungsmärkte im Rhein-Main-Gebiet ein relevantes Wahlkampfthema. Dabei dominiert die Bezahlbarkeit, teils differenziert in ländliche und urbane Räume oder einzelne Zielgruppen (CDU Hessen 2018: 61ff.; SPD Hessen 2018: 47ff.; BÜNDNIS 90/DIE GRÜNEN Hessen 2018: 103ff.; DIE LINKE Hessen 2018: 7ff.). Konkret für Senior*innen und Menschen mit Behinderungen werben viele Parteien für die Förderung von »seniorengerechtem Umbau « oder vom selbstbestimmten Wohnen und alternativen Wohnformen. Dabei richten sich die Programme stärker an einer finanziellen Förderung oder Beratungsangeboten aus, als regulative Maßnahmen $\mathrm{zu}$ einer verbindlichen Verankerung $\mathrm{zu}$ fordern (CDU Hessen 2018: 82ff.; SPD Hessen 2018: 125ff; BÜNDNIS 90/DIE GRÜNEN Hessen 2018: 105; DIE LINKE Hessen 2018: 7ff., 42, 124). Die FDP spricht sich zwar ebenfalls für Inklusion und die Förderung neuer Wohnformen aus, fordert aber zugleich als einzige etablierte Par- 
tei eine stärkere Marktwirtschaft im Wohnungsbau: »Der Staat ist [...] Kostentreiber und Wohnungsverhinderer Nummer eins. Bürokratie, Auflagen und baubedingte Steuern [...] bremsen private Investitionen im Wohnungsbau« (FDP Hessen 2018: 105, vgl. auch 9, 65). Die AfD erwähnt als einzige Partei »Barrierefreiheit« nicht in ihrem Wahlprogramm und fordert einschränkend »Inklusion mit Augenmaß (AfD Hessen 2018: 47). Für die Wohnungspolitik attestiert sie ein Staatsversagen und fordert wie die FDP einen Bürokratieabbau mit einer stärkeren marktwirtschaftlichen Orientierung (ebenda: 67ff.).

Im Vergleich zu den Wahlprogrammen werden die Koalitionsverträge der beiden letzten schwarz-grünen Regierungen etwas konkreter in ihren politischen Vorhaben. 2014 wird noch allgemein erklärt, dass »bei der Schaffung und Sanierung von Wohnraum insbesondere Barrierefreiheit und energetische Sanierung wichtige Kriterien « sind (Landesregierung Hessen 2014: 83). Im Jahr 2019 bleibt die Unterstützung von seniorengerechtem und barrierefreiem Umbau erhalten, hier aber klar auf den Bestandsumbau bezogen. Zudem liegt der Fokus auf innovativen Wohnformen und dem Ziel, die Wohnberatung »Selbstbestimmt im Alter « auszubauen (Landesregierung Hessen 2019: 15, 23). Der Themenschwerpunkt auf gemeinschaftliches Wohnen wird dabei stark von Bündnis 90/Die Grünen eingebracht (IP 19: 15ff., 51) und insgesamt sind Modellprojekte zum barrierefreien bzw. -reduzierten Wohnraum als Bestandteil alternativer Wohnformen das präferierte Mittel der schwarz-grünen Landesregierung (Hessischer Landtag 2017a: 7479; Hessischer Landtag 2017c: 1).

Zusammenfassend setzen sich mit Ausnahme der AfD alle Parteien für den barrierefreien bzw. -reduzierten Wohnraum ein. Generell geht aus den Wahlprogrammen und Koalitionspapieren eine Präferenz für ökonomische und informationelle Steuerung hervor. Dieser Eindruck verstärkt sich durch die geführten Interviews, die allen etablierten Parteien eine Beschäftigung mit diesem Thema bescheinigen (IP 7: 36; IP 15: 99; IP 16: 81; IP 47: 22; IP 48: 46; IP 49:3; IP 53: 5). Es handelt sich zumindest offiziell um ein sogenanntes valence issue mit konsensualer Zieldefinition: »Das wird ja niemand offen sagen. Also, man kann ja schlecht sagen: Ich bin jetzt dagegen, dass arme, alte, schwache, kranke Menschen jetzt halt einfach Pech haben und weniger Wohnraum kriegen« (IP 14: 54). Parteipolitische Unterschiede zeigen sich hingegen in der Priorisierung politischer Vorhaben (IP 7: 40; IP 18: 83; IP 20: 62; IP 47: 22; IP 50: 16). Hier attestieren einige Interviewpartner*innen der LINKEN, der SPD und Bündnis 90/Die Grünen als Interessenvertretungen von Betroffenengruppen eine stärkere Aktivität (IP 10: 60; IP 12: 58ff.; IP 14: 54). Gleichzeitig basieren diese Zuschreibungen insbesondere auf der allgemeinen wohnungspolitischen Einschätzung, die sich entlang der Scheidelinien Eigentum-Mietwohnraum und Regulierung-Deregulierung manifestiert (IP 19: 13; IP 20: 24, 36; IP 53: 39). Die konkreten parteipolitischen Schwerpunktsetzungen zeigen sich erst in der Analyse einzelner Policies (vgl. Kapitel 7.2.5.2 bis 7.2.5.4).

\section{Ministerialverwaltung}

Unter »Institutionen« wurde bereits der ministerielle Zuschnitt herausgearbeitet, der in Hessen für die sozial- und wohnungspolitischen Bereiche des barrierefreien bzw. -reduzierten Wohnraums zuständig ist (vgl. Kapitel 7.2.4). Im Gegensatz zu den außerparlamentarischen Interessengruppen und den Parteien formuliert die Ministerial- 
verwaltung allerdings keine eigenen Politikziele, vielmehr gilt sie formal als Entscheidungshelferin der Landesregierung und setzt die Vorgaben der Ministeriumsspitze um (vgl. Kapitel 4.6.3). Inwiefern Akteure aus der Ministerialverwaltung dennoch die politischen Prozesse beeinflussen und inwieweit ihnen eigene wert- oder zweckrationale Interessen zu unterstellen sind, ist am konkreten empirischen Fall zu überprüfen.

\subsubsection{Bauordnung}

Für die Analyse der politischen Prozesse zu bauordnungsrechtlichen Vorgaben ist insbesondere die letzte Novellierung der Hessischen Bauordnung der Jahre 2017/18 relevant (vgl. Abbildung 29). Im Sinne einer inkrementellen Politikgestaltung waren aber auch politische Aktivitäten vor und nach der konkreten Gesetzesnovellierung zu identifizieren.

Abbildung 29: Verlaufder der hessischen Bauordnungs-Novellierung (eigene Darstellung)

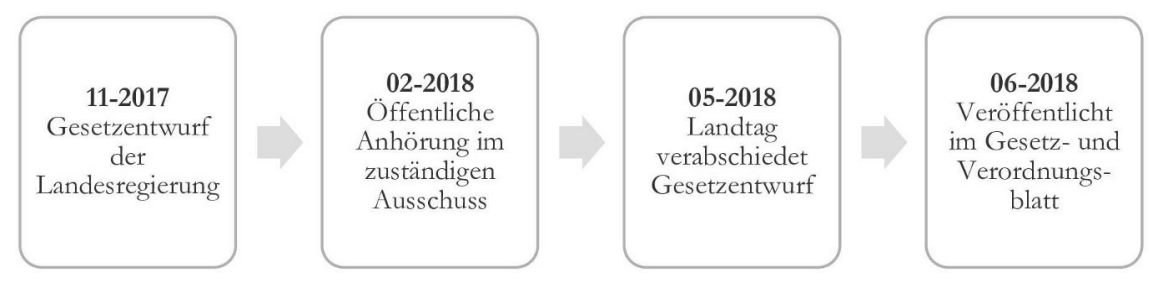

Die aktuellen bauordnungsrechtlichen Inhalte zum barrierefreien Bauen wurden bereits dargestellt (vgl. Kapitel 7.2.1) und können als Ergebnis der bisherigen politischen Prozesse gewertet werden. Ebendiese politischen Prozesse sind im Folgenden detailliert zu untersuchen.

\section{Außerparlamentarische Interessen}

Verschiedene außerparlamentarische Interessen haben sich in den Novellierungsprozess zur Bauordnung eingebracht. Die Analyse der offiziellen Stellungnahmen offenbart zwei Koalitionen, die sich in die Angebotsseite und die Nachfrageseite nach Wohnraum einteilen lassen (vgl. Abbildung 30). Trotz eigener Schwerpunktsetzungen sind die übergeordneten Interessen dieser beiden Koalitionen in sich weitestgehend homogen. So argumentiert die Angebotsseite von Wohnraum gegen eine strengere Auslegung der Barrierefreiheit im Ordnungsrecht und begründet dies mit entstehenden Mehrkosten sowie der damit verbundenen Zielsetzung, das Bauen weniger bürokratisch zu gestalten. Die AWI erklärt, dass ihre Mitgliedsunternehmen bereits aktuell viele Projekte zum Wohnen für ältere Menschen oder Menschen mit Behinderungen umsetzen würden, »ohne hierbei einem weitgehenden gesetzlichen Zwang unterlegen zu sein « (Hessischer Landtag 2018g: 321). Ein AWI-Mitglied benennt dabei die Musterbauordnung als Leitlinie, womit das Bauen über die Landesgrenzen erleichtert würde. Zudem sei das ARGEBAU-Muster vielfach nicht so tiefgreifend in seiner Regulation (IP 12: 95ff.). Darüber hinaus dürften neue Regelungen nicht im Widerspruch zum bezahlbaren Wohnen stehen (Hessischer Landtag 2018g: 310, vgl. auch Problemstrukturen in Kapitel 7.2.2). Konkret zur Barrie- 
refreiheit wird die VhU am deutlichsten: "Die gesetzlichen Vorgaben für barrierefreies Bauen sind große regulatorische Kostentreiber. [...] Viele Bestimmungen für Barrierefreiheit sind überzogen und unnötig kompliziert« (Hessischer Landtag 2018j: 368).

Abbildung 30: Koalitionen bei der hessischen Bauordnungs-Novellierung (eigene Darstellung)

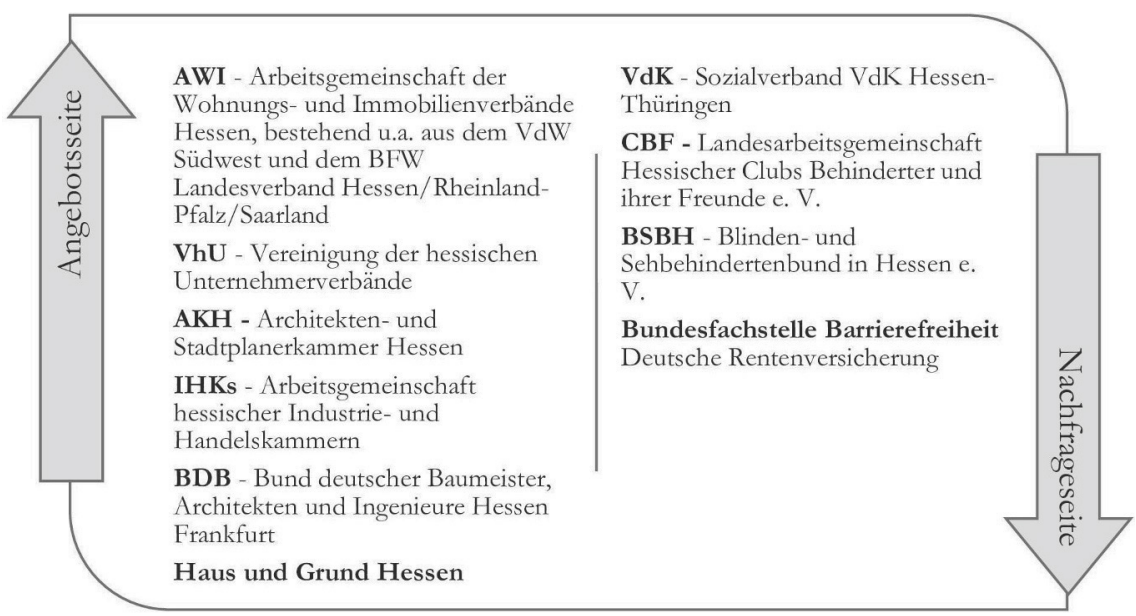

Die Nachfrageseite nach Wohnraum hingegen setzt sich für eine stärkere Verankerung der Barrierefreiheit in der Hessischen Bauordnung ein und gilt damit als Veränderungsinteresse: Es werden Vorschläge zur Barrierefreiheit formuliert, die über den bisherigen Gesetzentwurf und teils über die Musterbauordnung hinausgehen. Klare Orientierungslinien zur Bewertung des Gesetzentwurfs sind inklusionspolitische Leitlinien nach der UN-BRK, aber auch Sicherheit und Gefahrenabwehr.

Im Folgenden wird konkretisiert, welche Positionen die jeweiligen Interessengruppen vertreten und mithilfe welcher Strategien sie versuchen, diese in der Gesetzesnovellierung umzusetzen.

Interessen und Argumente

Bei der Novellierung der Bauordnung waren viele Regelungen zur Barrierefreiheit umstritten. Zwar wird im Folgenden der Fokus zunächst auf den einschlägigen $\$ 54$ gelegt, aber anschließend sind auch Diskussionen zu Wohnungen im Allgemeinen ( $\$ 51)$, zur Definition (\$ 2), zu Aufzügen ( $\$ 42)$ und Treppen sowie Rettungswegen (\$\$ 36, 37) zu erörtern. Damit können nicht vollumfänglich alle die Barrierefreiheit betreffenden Regelungen umfasst werden, wohl aber die mutmaßlich zentralsten und politisch umstrittensten.

Im $\$ 54$ sehr greifbar ist die 20-Prozent-Regelung, nach der Wohnungen nicht wie bislang in einem Geschoss bestimmten Anforderungen an die Barrierefreiheit entsprechen müssen, sondern diese Vorgabe sich nun auf 20 Prozent der Wohnungen in einem Gebäude beziehen (vgl. Kapitel 7.2.1). Der Gesetzentwurf des Jahres 2017 enthielt diesen Vorschlag bereits. Hier ist interessant, dass verschiedene Interessengruppen schon im Sommer 2017 Stellungnahmen abgegeben hatten - also vor der Aufforderung zur 
schriftlichen Stellungnahme (vgl. Abbildung 29). So fordern die IHKs und der BDB bereits im Juli 2017 eine Änderung der damals geltenden Regelung:

»Die >Quotenregelung< [...] führt ohnehin in der Praxis dazu, dass mit überbordendem Aufwand Wohnungen geschaffen werden, die mit aller Wahrscheinlichkeit nicht von einem Menschen mit Handicap bezogen werden und im Normalfall Nutzungseinschränkungen, wie z.B. durch überbreite Türen und die zugehörigen Bewegungsflächen bei der Möblierung, mit sich bringen « (Hessischer Landtag 2018g: 2, vgl. auch Hessischer Landtag 2018i: 174ff.).

Der Gesetzentwurf vom November 2017 formuliert schließlich eine neuartige 20Prozent-Regelung, wie sie bislang in noch keinem anderen Bundesland besteht (vgl. Kapitel 6.1.3). Diese Änderung wird von der AKH sowie Haus und Grund ausdrücklich begrüßt (Hessischer Landtag 2018g: 67; Hessischer Landtag 2018i: 245). Die AWI schlägt indessen ein »Günstigkeitsprinzip« vor, nachdem entweder nach der bisherigen Regelung zu Wohnungen eines Geschosses oder nach der 20-Prozent-Regelung gebaut werden dürfe, sodass »ein verpflichtendes $>$ Mehr an barrierefrei erreichbaren Wohnungen gegenüber bisher vermieden wird « (Hessischer Landtag 2018g: 322). Tendenziell spricht sich die Angebotsseite von Wohnraum gegen flächendeckende Quoten für ganz Hessen aus und begründet dies mit regional unterschiedlichen Bedarfen (IP 12: 10ff.; IP 48: 19ff.). Laut VhU seien derartige Quoten wenig zielsicher, da viele dieser Wohnungen nicht von Menschen mit Behinderungen bewohnt würden - die schwierige Steuerung von Angebot und Nachfrage nach entsprechendem Wohnraum kommt hier zum Tragen (Hessischer Landtag 2018j: 368, vgl. Kapitel 7.2.2).

Die Nachfrageseite wird offiziell erst mit dem Gesetzentwurf vom November 2017 aktiv. Insbesondere der Club Behinderter und ihrer Freunde (CBF) sowie der VdK kritisieren die geplante 20-Prozent-Regelung scharf. Bei kleineren Wohngebäuden führe diese zu weniger Wohnungen mit barrierefreien Kriterien, was insbesondere in ländlichen Regionen problematisch sei. Zudem seien 20 Prozent etwa bei drei oder vier Wohnungen nicht eindeutig zu bestimmen (Hessischer Landtag 2018a: 44; Hessischer Landtag 2018g: 336). Ein Gesprächspartner berichtet aus der Anhörung:

»Wir haben uns dann mal von einem großen Wohnungsdienstleister [...] herausgeben lassen, wie sein kompletter Wohnungsbestand zusammengesetzt ist [...], dass, würden die jetzt den gesamten Wohnungsbestand nach der neuen Bauordnung bauen, sie viel, viel weniger barrierefreie Wohnungen hätten« (IP 46: 49ff.).

Eine andere Interviewpartnerin kritisiert, dass bereits im Vorfeld ein Gespräch mit der Obersten Bauaufsicht stattgefunden habe, wobei die 20-Prozent-Regelung kein Thema gewesen sei. Die nachträgliche Änderung sei intransparent und ohne erneute Rücksprache erfolgt (IP 14: 32). Letztlich wurde diese Regelung nicht mehr verändert und wie im Gesetzentwurf formuliert verabschiedet.

Eine zweite kontroverse Änderung bezieht sich auf die Ausstattungskriterien zur Barrierefreiheit und insbesondere auf die Rollstuhlgerechtigkeit. Bislang mussten die entsprechend herzustellenden Wohnungen barrierefrei erreichbar und Räume darin mit dem Rollstuhl zugänglich sein. Der Gesetzentwurf sieht nun eine Formulierung vor, die sich an der Musterbauordnung des Jahres 2012 orientiert (vgl. Kapitel 6.1.2). In 
der Praxis bedeutet dies einerseits, dass neben der Erreichbarkeit bis zur Wohnungseingangstür nun auch die Zugänglichkeit - inklusive Wohnungseingangstür - sowie die nachträglich leichter herzustellende barrierefreie Nutzbarkeit festgeschrieben werden. Andererseits entfällt das Kriterium zur Rollstuhlgerechtigkeit. Die Angebotsseite von Wohnraum begrüßt diese Änderung prinzipiell. Bereits ein Impulspapier des BDB aus dem Juli 2017 erörtert zur bisherigen rollstuhlgerechten Zugänglichkeit: »So führen z.B. die geforderten Türabmessungen und die zugehörigen Bewegungsflüchen zu überdimensionierten Wohnungen, schlecht möblierbaren Grundrissen und Spezialbauteilen. [...] was neben entsprechend höheren Kosten auch zu einer generell schlechteren Akzeptanz durch die Nutzer führt « (Hessischer Landtag 2018g: 7). Angeregt wird stattdessen, Bewegungsmaße und Türdurchgangsbreiten nach der DIN 18040-2 ohne R-Anforderung vorzugeben. Diese ließen sich deutlich einfacher anwenden, sogar prinzipiell auf alle Wohnungen (ebenda: 3ff.). Der Gesetzentwurf vom November 2017 streicht schließlich die Rollstuhlgerechtigkeit aus der Bauordnung. Für den späteren Umbau im Bedarfsfall verweist Haus und Grund auf ökonomische Fördermöglichkeiten (Hessischer Landtag 2018g: 67, vgl. auch Hessischer Landtag 2017d: 96).

Die Nachfrageseite nach Wohnraum befürwortet zwar die geplante barrierefreie Zugänglichkeit und leicht herzustellende Nutzbarkeit (Hessischer Landtag 2018g: 274f., 337), kritisiert aber das Entfallen der Rollstuhlgerechtigkeit scharf. So sei der Mehrverbrauch an Flächen bei vorausschauender Planung gering, wofür der CBF eine Studie der Obersten Bayerischen Bauaufsicht zitiert (Hessischer Landtag 2018g: 337f.). Sowohl CBF als auch VdK sehen in der Neuformulierung von $\$ 54$ Abs. 1 einen Verstoß gegen die UN-BRK, nach der Menschen mit Behinderungen ein Recht auf die freie Wahl ihres Wohnorts haben (Hessischer Landtag 2018a: 44; Hessischer Landtag 2018g: 337f.). Auch die Bundesfachstelle Barrierefreiheit empfindet die rein finanzielle Förderung für rollstuhlgerechten Wohnraum als ungenügend und empfiehlt stattdessen analog zur rheinland-pfälzischen Bauordnung eine Quote im Bauordnungsrecht (Hessischer Landtag 2018h: 99, vgl. auch Kapitel 6.1.3). Ein Interessenvertreter von Menschen mit Behinderungen erklärt zudem, dass die hessische Richtlinie zur Wohnraumförderung auch nach einer späteren Überarbeitung die Entscheidung, ob und in welchem Umfang rollstuhlgerechter Wohnraum hergestellt werden müsse, den Kommunen überlassen habe (IP 8: 6).

Eine dritte Kontroverse zum $\$ 54$ bezieht sich auf den schwellenlosen Zugang zum Freisitz. Eine entsprechende Regelung findet sich bereits in einigen Bundesländern, ist aber in der Musterbauordnung des Jahres 2012 nicht enthalten (vgl. Abbildung 18). Hier erinnert sich eine parteipolitische Interviewpartnerin: »[Da] haben die Investoren und diejenigen, die bauen sollen, aufgeschrien, als es darum ging, dass jegliche Freisitze barrierefrei sind (IP 19: 3, vgl. auch IP 49: 39). Sowohl der VdW als auch die VhU begründen ihre Ablehnung mit aufwendigen, teuren baulichen Lösungen (Hessischer Landtag 2018a: 33f.; Hessischer Landtag 2018j: 372). Aber auch mögliche Rechtswidersprüche werden von der Angebotsseite ins Feld geführt, da eine Flachdachrichtlinie dem geforderten schwellenlosen Übergang zum Balkon oder zur Terrasse im Wege stünde (vgl. Kapitel 7.2.2). Zudem handele es sich bei »schwellenlos« um einen rechtlich unbestimmten Begriff, was wiederum Rechtsunsicherheit nach sich zöge (Hessischer Landtag 2018g: 323; Hessischer Landtag 2018g: 3; Hessischer Landtag 2018i: 178). Insbesondere der CBF 
lobt die geplante Änderung hingegen (Hessischer Landtag 2018g: 337). Ein CBF-Mitglied erklärt im Interview, dass die DIN 18040-2 hier durchaus klar formuliere und generell eine Nullschwelle vorschreibe. Sofern Schwellen »technisch unabdingbar« sind, dürften sie bis zu zwei Zentimeter hoch sein. Inzwischen sei die technische Unabdingbarkeit allerdings durch neue Konstruktionslösungen nicht mehr gegeben, und so sei es auch in der hessischen Verwaltungsvorschrift formuliert (IP 46: 11ff., vgl. auch HMWEVW 2018b: 63).

Die vierte und letzte Kontroverse zum $\$ 54$ handelt vom unverhältnismäßigen Mehraufwand. Hier schlägt der Gesetzentwurf eine Straffung des Textes vor, indem auf die Nennung einzelner Tatbestände verzichtet und stattdessen formuliert wird: »[...] gelten nicht, soweit sie nur mit einem unverhältnismäßigen Mehraufwand umgesetzt oder aus bautechnischen Gründen nicht erfüllt werden können « (vgl. Kapitel 7.2.1). Diese Änderung wird sowohl von der Angebots- als auch von der Nachfrageseite nach Wohnraum kritisiert. Während die AWI befürchtet, dass zukünftig weniger Ausnahmen genehmigt würden (Hessischer Landtag 2018g: 324), hält die Bundesfachstelle Barrierefreiheit das Gegenteil für denkbar (Hessischer Landtag 2018h: 99). Generell setzen sich verschiedene Behindertenverbände sowie der VdK für die komplette Abschaffung dieser Klausel ein und verweisen dafür sowohl auf die UN-BRK als auch auf positive Beispiele in Thüringen (Hessischer Landtag 2018g: 274f., 298).

Neben dem einschlägigen $\$ 54$ tangieren viele weitere Paragraphen der Hessischen Bauordnung das barrierefreie Bauen und waren in der Novellierung 2018 umstritten. So steht eine Änderung im $\$ 51$ Wohnungen in der Kritik der Wohnungs- und Bauwirtschaft, nach der die Abstellräume »ausreichend groß« und »schwellenlos zugänglich» sein sollen (HMWEVW 2018a: 50). Neben der AWI kritisiert auch der BDB diese Regelung als über die Musterbauordnung hinausgehend und als rechtlich unsicher durch unbestimmte Rechtsbegriffe (Hessischer Landtag 2018g: 317; Hessischer Landtag 2018g: 2). Die letztlich verabschiedete Bauordnung hält trotz dieser Kritik an der Vorgabe fest. Umgekehrt beanstanden die Behinderten- und Sozialverbände in $\$ 2$ (8) die Definition von Barrierefreiheit: Der Gesetzentwurf orientiert sich an dem zum Frühjahr 2018 gültigen Hessischen Behinderten-Gleichstellungsgesetz. Gleichzeitig sei dieses laut Blinden- und Sehbehindertenbund "schon wieder überholt«, da eine 2016 novellierte Fassung des entsprechenden Bundesgesetzes neben der Zugänglichkeit und Nutzbarkeit auch die Auffindbarkeit als Kriterium der Barrierefreiheit definiert habe (Hessischer Landtag 2018a: 40, vgl. auch BMAS 2016a: 3). Das HessBGG wurde darauffolgend im Jahr 2019 novelliert und enthält seitdem ebenfalls die Auffindbarkeit, wohingegen die kurz zuvor verabschiedete Bauordnung noch bei der alten Fassung ohne dieses Kriterium verblieben ist (vgl. Bürgerservice Hessenrecht 2020, vgl. Kapitel 7.2.4). Hier zeigt sich die Zeitverzögerung, mit der das Disability Mainstreaming in den unterschiedlichen Politikfeldern Einzug hält.

Ferner ist $\$ 42$ zu Aufzügen ein Streitpunkt. So befürwortet die Angebotsseite zwar einerseits die vorgesehenen Entlastungen für den nachträglichen Aufzugseinbau. Andererseits entfällt eine Regelung, nach der Haltestellen im obersten Geschoss sowie im Kellergeschoss nicht vorgehalten werden müssen, sofern dies nur mit »besonderen Schwierigkeiten « möglich wäre. Hier befürchtet die AWI deutliche Mehrkosten, Haus und Grund sieht den entstehenden bautechnischen Aufwand als unverhältnismäßig zum 
entstandenen Nutzen an (Hessischer Landtag 2018g: 316; Hessischer Landtag 2018g: 64). Die Nachfrageseite begrüßt diese Änderung zwar, sieht aber Nachbesserungsbedarf: »\$ 42 ist für uns ein Problem. Inklusion bedeutet, dass Menschen mit Behinderung überall dabei sein sollen. So sollte jeder Aufzug - wenn es kein Lastenaufzug oder ein völlig unnötiger Aufzug istzur Nutzung mit dem Rollstuhl geeignet sein « (Hessischer Landtag 2018a: 42, vgl. auch Hessischer Landtag 2018g: 276, 329). An dieser Stelle wurde vom Gesetzgeber nachjustiert und die letztlich verabschiedete Bauordnung schreibt vor, dass alle Aufzüge - nicht wie bisher lediglich einer pro Gebäude - zur Aufnahme von Rollstühlen geeignet sein müssen (HMWEVW 2018a: 45f.). Einer Forderung des BSBH, nach der Bedienelemente der Aufzüge für blinde und sehbehinderte Menschen nutzbar sein müssten, wurde hingegen nicht nachgegeben (Hessischer Landtag 2018g: 301).

Schließlich wurde emotional zu barrierefreien Rettungswege und Treppen diskutiert ( $\$ \$ 36,37)$. Insbesondere, dass der erste Rettungsweg häufig über eine Treppe führt - und damit für Menschen im Rollstuhl nicht nutzbar ist - wird von Behindertenund Sozialverbänden scharf angegriffen (Hessischer Landtag 2018a: 42). Aber auch die Belange von Menschen mit Seh- und Hörbehinderungen würden nicht ausreichend berücksichtigt. Die nicht gewährleistete selbstständige Flucht verstoße gegen die UNBRK und das Grundgesetz (Hessischer Landtag 2018g: 329, 276, 298). Der Forderung nach einem gleichwertigen ersten - barrierefreien - Rettungsweg kommt die novellierte Bauordnung indessen nicht nach. Und in $\$ 37$ (6) Treppen sieht der Gesetzentwurf Handläufe auf beiden Seiten sowie Zwischenhandläufe vor, "soweit die Verkehrssicherheit oder Barrierefreiheit dies erfordert (HMWEVW 2018a: 39). Der Hinweis auf Barrierefreiheit ist neu, was von den IHKs und dem BDB mit Blick auf Kostensteigerungen als unverhältnismäßig kritisiert wird (Hessischer Landtag 2018g: 2; Hessischer Landtag 2018i: 176). Umgekehrt erklären die Behindertenverbände Treppen als Unfallschwerpunkt und fordern eine ausnahmslose Anbringung von beidseitigen Handläufen. Zudem würden Aspekte der Treppensicherheit für Menschen mit Sinnesbeeinträchtigungen fehlen etwa Treppenkantenmarkierungen oder eine gute Ausleuchtung (Hessischer Landtag 2018a: 41; Hessischer Landtag 2018g: 276, 335; Hessischer Landtag 2018h: 96f.). Das verabschiedete Gesetz hält letztlich an dem Gesetzentwurf fest und berücksichtigt damit weder die vorgebrachte Kritik der Angebots- noch der Nachfrageseite.

Es lässt sich resümieren, dass der in der Anhörung diskutierte Gesetzentwurf nur in einem einzigen Punkt zur Barrierefreiheit nachjustiert worden ist. Einzig im $\$ 42$ wurde die Forderung von Behinderten- und Sozialverbänden aufgenommen, nach der alle Aufzüge zur Aufnahme von Rollstühlen geeignet sein müssen. Die Definition von Barrierefreiheit ( $\$ 2, A b s .8)$ sowie die Regelungen zu Rettungswegen und Treppen ( $\$ \$$ $36,37$ ), zu Wohnungen ( $\$ 51)$ und zum barrierefreien Bauen $(\$ 54)$ wurden trotz Kritik unverändert verabschiedet. Diese Kritik kam teils von der Angebots-, aber insbesondere von der Nachfrageseite nach Wohnraum. Im Vergleich zur vorherigen Fassung der Bauordnung aus dem Jahr 2011 haben dennoch einige Änderungen bereits vorab Einzug in den Gesetzentwurf gefunden - so etwa die von den Behinderten- und Sozialverbänden scharf kritisierte 20-Prozent-Regelung. Deshalb ist es im weiteren Verlauf wichtig, den Blick auf inkrementelle und vor allem frühzeitige Formen der politischen Einflussnahme zu lenken. 


\section{Ressourcen und Strategien}

Über welche Ressourcen verfügen die Angebots- und Nachfrageseite zur Durchsetzung ihrer Interessen? Für die Wohnungs- und Bauwirtschaft ist ein starker Bezug zu ihrer strukturellen Macht nachzuzeichnen, nach der sie für die politisch gewollte Bereitstellung von Wohnraum unabdingbar ist. Ein AWI-Mitglied erklärt, dass überzogene regulative Anforderungen das Bauen verteuern und insbesondere in konjunkturellen Rezessionen zu einer reduzierten Bautätigkeit führen (IP 48: 2, 36). Ein Behindertenvertreter beschreibt den Druck, der dadurch auf die politischen Entscheider*innen ausgeübt wird, wie folgt: »Immer die Argumentation: >Ja, ihr wollt doch das gebaut wird, preiswerter Wohnraum. Aber dann muss die Barrierefreiheit weg« (IP 8: 73ff., vgl. auch IP 15: 9, 19ff.). Umgekehrt sei es laut einem AWI-Mitglied äußerst schwierig, aus ökonomischer Perspektive gegen die normativen Forderungen von Inklusion und Gefahrenabwehr zu argumentieren (IP 12: 70, 118).

Dies leitet bereits über zu den Ressourcen der Nachfrageseite nach Wohnraum. Da die Behinderten- und Sozialverbände über keine strukturelle Macht auf den Wohnungsmärkten verfügen, versuchen sie, ihre Positionen durch ihre fachliche Expertise zu stärken. In den Stellungnahmen verweisen der BSBH sowie der CBF auf ihre Mitglieder, die vielfach langjährig als kommunale Behindertenbeauftragte oder in entsprechenden Beiräten aktiv seien (Hessischer Landtag 2018g: 298, 329). Ferner erläutern der VdK und die Bundesfachstelle Barrierefreiheit langfristig entstehende Kosten, die durch heute ausbleibende Investitionen entstünden. Dies betrifft den nachträglich aufwendigeren Umbau oder den Umzug in stationäre Einrichtungen (Hessischer Landtag 2018a: 43ff.). Da diese Argumente längere Zeithorizonte umfassen und teils andere Politikfelder betreffen - etwa die Pflegepolitik -, sind sie in der Bauordnungsnovellierung allerdings wenig wirkmächtig.

Außerdem wurde durch bereits im Gesetzentwurf vorliegende Änderungen wie die 20-Prozent-Regelung deutlich, wie wichtig neben der formalisierten Beteiligung im Anhörungsverfahren eine frühzeitige Interessenvertretung ist. Dies zeigten für die Angebotsseite von Wohnraum die Stellungnahmen aus dem Sommer 2017, aber auch für die Nachfrageseite nach Wohnraum lassen sich inkrementelle Lobbying-Strategien nachzeichnen. So hat der VdK bereits Ende 2017 eine Stellungnahme eingereicht - jedoch nicht beim zuständigen Wirtschaftsministerium, sondern beim Sozialministerium. Die darin vorgeschlagenen Änderungen fanden im Gesetzentwurf keine Berücksichtigung (Hessischer Landtag 2018g: 274f.). Zwei CBF-Mitglieder berichten zudem von einem frühzeitigen Termin bei der Obersten Bauaufsicht (IP 8: 45ff., 67; IP 46: 41) und auch der VdK sei über die Aktionspläne zur Umsetzung der UN-BRK im Bereich Bauen/Wohnen aktiv gewesen: "Und wir-oder, die unterschiedlichen Verbände - hatten dann das Gremium der UN-Behindertenrechtskonvention genutzt, um halt auch darauf Einfluss zu nehmen, weil es verstrickt sich ja alles« (IP 14: 32ff.). In diesem Kontext konnte ein frühzeitiger Referentenentwurf diskutiert werden, worin allerdings die 20-Prozent-Regelung noch nicht enthalten war (ebenda). Letztlich habe der CBF an dem Tag, an dem im Landtag über die Bauordnung abgestimmt wurde, eine Petition als Tischvorlage an alle Abgeordneten ausgeteilt sowie persönliche Gespräche mit den Abgeordneten gesucht, um seine Kritikpunkte noch einmal hervorzubringen (IP 46: 41). 
Betrachtet man im Ergebnis die verabschiedete Bauordnung, beurteilt die AWI als Vertretung der Wohnungs- und Bauwirtschaft die Neuregelung zum $\$ 54$ als »durchaus [...] angemessen, verhältnismäßig und praxisorientiert « (Hessischer Landtag 2018g: 322). Umgekehrt beanstandet der CBF, dass weniger Wohnraum für Menschen mit Behinderungen entstünde und dieser durch das Wegfallen der R-Anforderung von schlechterer Qualität sei (Hessischer Landtag 2018g: 337). Die Bundesfachstelle Barrierefreiheit erklärt, \$54 (1) könne »vor dem Hintergrund des jedenfalls teilweise in Deutschland schon erreichten Standes der Barrierefreiheit nicht als angemessene Umsetzung der BRK angesehen werden « (Hessischer Landtag 2018h: 98).

Aus diesem Grund initiiert der VdK im Anschluss an die Bauordnungsnovelle eine Online-Petition (IP 14: 32, 64). Die Petition als Instrument der öffentlichen Aufmerksamkeit lief unter dem Titel »Die neue Hessische Bauordnung verschlechtert die Lage für Menschen mit Behinderungen. Die Paragraphen 2 und 54 müssen dringend geändert werden! «(VdK Hessen-Thüringen 2018: 1). Es wird ein Verstoß gegen die UN-BRK und den Artikel 3 (4) des Grundgesetzes gesehen - niemand darf wegen seiner Behinderung benachteiligt werden. Deshalb fordert der VdK eine Rückkehr zur vorherigen Regelung nach Geschossen sowie zur rollstuhlgerechten Nutzung. Aber auch der Ausnahmetatbestand zum unverhältnismäßigen Mehraufwand solle aufgehoben und die Definition zur Barrierefreiheit durch die Auffindbarkeit ergänzt werden (VdK Hessen-Thüringen 2018: 2ff.). Bis zum Juni 2019 unterzeichneten mehr als 24.000 Menschen die Petition, welche im Anschluss an den Petitionsausschuss des Landtags überwiesen wurde (VdK HessenThüringen 2019; Hessischer Landtag 2020c). Im März 2020 war ein Runder Tisch mit dem Wirtschaftsministerium geplant, der aber durch die Corona-Pandemie vertagt werden musste. Corona als situativer Aspekt wirkt hier als Unmöglichkeitsfenster, das politische Prozesse verzögert. Ohnehin erklärt aber der wohnungspolitische Sprecher einer Regierungsfraktion: "[D]as, was wir jetzt hier als Gegenstand in der Petition haben, das war ja schon in der Diskussion seinerzeit bei der HBO-Änderung. [...] das wird jetzt kein Punkt sein, dass wir die HBO deshalb neu anpacken « (IP 53: 17, vgl. auch IP 49: 7ff.). Dennoch stellt dieses Outside-Lobbying aber eine sehr öffentlichkeitswirksame, konfrontative Form der politischen Einflussnahme dar. Auch bei der im Anschluss an die Bauordnungsnovelle stattfindenden Novellierung des Hessischen Behinderten-Gleichstellungsgesetzes nutzt der VdK seine Stellungnahme, um die bauordnungsrechtlichen Regelungen zur Barrierefreiheit erneut zu kritisieren (Hessischer Landtag 2018k: 41f.).

Die langfristige Wirkung politischer Einflussnahme wird außerdem daran deutlich, dass bereits ein Jahr nach der Novellierung eine erneute Überarbeitung der Bauordnung diskutiert wird. Im Dezember 2019 reichen CDU und Bündnis 90/Die Grünen eine Änderung zum seriellen Bauen ein, begründet durch die Notwendigkeit des schnelleren und bezahlbareren Bauens (Hessischer Landtag 2019b: 2072ff.). Damit wird eine Forderung der AWI aus der Bauordnungsnovellierung des Jahres 2018 aufgegriffen (Hessischer Landtag 2018a: 33; AWI-Hessen 2018). Auf einen FDP-Gesetzentwurf aus dem Sommer 2019 und darauffolgend den Gesetzentwurf der Landesregierung im Dezember 2019 findet im Frühjahr 2020 eine öffentliche Anhörung statt (Hessischer Landtag 2019a; Hessischer Landtag 2020b). Zeitnahe Änderungen der Bauordnung sind also durchaus möglich, erscheinen aber im Nachgang zur Bauordnungsnovelle des Jahres 2018 in Bezug auf die Barrierefreiheit als politisch nicht durchsetzbar. 
Parteipolitik

Die inhaltlichen Diskussionslinien, die sich bereits bei den außerparlamentarischen Interessen gezeigt haben, setzen sich teilweise im parlamentarischen Raum fort. Aufbauend auf den bisherigen Erkenntnissen wird deshalb die Rolle von parteipolitischen Akteuren im Novellierungsprozess der Hessischen Bauordnung untersucht. Dies geschieht zunächst über eine Nachzeichnung des parlamentarischen Prozesses mit je parteipolitischen Schwerpunktsetzungen. Anschließend sind die fachpolitischen Scheidelinien zwischen Wohnungsbau- und Sozialpolitik zu diskutieren.

Der parlamentarische Prozess zur Novellierung der Bauordnung

Da sich Barrierefreiheit als inklusionspolitische Idee auf einen breiten gesellschaftlichen Konsens stützt, versuchen auch die meisten Parteien aus Motiven des VoteSeeking dieses Thema für sich aufzunehmen (IP 48: 46; IP 50: 42, vgl. Kapitel 7.2.5.1). Spezifisch zum barrierefreien Bauen rekurrieren dabei mehrere Abgeordnete aus Regierung und Opposition zugleich auf die Musterbauordnung als zentrale Referenz (IP 19: 3; IP 49: 15; IP 50: 44). Einerseits soll damit das länderübergreifende Bauen erleichtert werden, andererseits gilt es dennoch, die Spezialinteressen einzelner Verbände zu berücksichtigen. Hieraus ergibt sich ein Spannungsverhältnis, das sich insbesondere an der 20-Prozent-Regelung des $\$ 54$ entladen hat (IP 19: 7; IP 53: 9).

Im Gesetzentwurf vom November 2017 attestiert die Landesregierung mit Verweis auf den Koalitionsvertrag des Jahres 2014: "[D]ie Rechtslage in Bezug auf das barrierefreie Bauen [...] wird verbessert « (Hessischer Landtag 2017d: 64f.). Hier besteht ein interessantes Framing, das sich durch den gesamten politischen Prozess zieht: Sowohl Regierungsals auch unterschiedliche Oppositionsfraktionen formulieren das Ziel, Barrierefreiheit in der Bauordnung stärker integrieren zu wollen (Hessischer Landtag 2017b: 8381ff.). Was darunter verstanden wird und welche Abwägungen dabei getroffen werden, variiert derweil deutlich. So betonen Wirtschaftsminister Al-Wazir und die wohnungsbaupolitische Sprecherin der Grünen die geplante barrierefreie Zugänglichkeit, die leichtere nachträgliche Nutzbarkeit und den schwellenlosen Zugang zum Balkon. Die 20Prozent-Regelung wird damit begründet, dass Wohnungsbau vor allem im Ballungsraum stattfände und dort entsprechend höher gebaut würde, sodass diese Regelung zu einem Mehr an Barrierefreiheit führe (Hessischer Landtag 2017b: 9919ff.).

Zudem reichen die Regierungsfraktionen CDU und Bündnis 90/Die Grünen gemeinsam mit der FDP im Mai 2018 einen Änderungsantrag ein, der letztlich zur nachträglichen Regelung führt, nach der alle Aufzüge zur Aufnahme von Rollstühlen geeignet sein müssen (Hessischer Landtag 2018f: 2). Damit reagieren sie auf Anregungen der Behinderten- und Sozialverbände aus der öffentlichen Anhörung. Ein Änderungsantrag der SPD wird indessen abgelehnt. Danach hätten in »Gebäuden mit mehr als zwei Wohnungen [...] mindestens 20 Prozent der Wohnungen, jedoch mindestens die Wohnungen eines Geschosses barrierefrei erreichbar und zugänglich sein« müssen (Hessischer Landtag 2018e: 4). Die SPD-wohnungsbaupolitische Sprecherin hatte diesen Antrag mit dem VdK abgestimmt und auch in der zweiten Lesung zum Gesetzentwurf auf die Kritik der Behindertenund Sozialverbände an der geplanten Quotierung verwiesen (Hessischer Landtag 2018b: 9918; IP 49: 51). In derselben Lesung greift auch DIE LINKE verschiedene bislang nicht 
umgesetzte Forderungen aus der Anhörung auf, etwa die barrierefreien Rettungswege sowie die Orientierungen für Menschen mit Sinnesbeeinträchtigungen (Hessischer Landtag 2018b: 9921).

Letztlich wird die novellierte Bauordnung Ende Mai 2018 vom Landtag mit den Stimmen der Regierungsfraktionen und der FDP verabschiedet. Während DIE LINKE sich enthält, stimmt die SPD gegen das geplante Gesetz (Hessischer Landtag 2018c: 10126). Die anschließende Petition des VdK wird daraufhin aktiv von der wohnungsbaupolitischen Sprecherin der SPD unterstützt. Diese setzt sich auch für den Runden Tisch mit dem Wirtschaftsministerium ein: "Normal werden die im [Petitions-]Ausschuss einfach abgestimmt, also vorgetragen, abgestimmt, nimmt irgendjemand Stellung [...]. ich habe jetzt aber verlangt, dass da wenigstens ein Runder Tisch gemacht wird, um auch dem VdK, der sich ja sehr viel Mühe damit gegeben hat -ist der größte Sozialverband Deutschlands - [entgegenzukommen] « (IP 49: 9). Der Eindruck einer aktiven Rolle der SPD wird durch die Einschätzung eines Interessenvertreters von Menschen mit Behinderungen etwas gedämpft: Der Interviewpartner - selbst stark in den politischen Prozess involviert - bescheinigt der SPD eher "wenig Knowhow « und »nicht wirklich Engagement « mit Ausnahme von einzelnen Personen (IP 46: 73). Nichtsdestotrotz zeigen die Plenardebatten, der SPD-Änderungsantrag und das nachträgliche Einsetzen für die VdK-Petition, dass auch oppositionelle Parteien die Debatten zur Hessischen Bauordnung mitgeprägt haben.

\section{Scheidelinie der Fachressorts Bauen und Soziales}

Die in der theoretischen Vorarbeit ausgearbeitete Scheidelinie zwischen wohnungsbauund sozialpolitischen Fachpolitiker*innen ist bei der hessischen Bauordnungsnovellierung kaum relevant (vgl. Kapitel 4.6.2). Weder in den parlamentarischen Prozessen noch in der Kontaktaufnahme zur Interviewführung sind sozialpolitische Sprecher*innen hervorgetreten. Vielmehr haben sich direkt die wohnungsbaupolitischen Sprecher*innen für den barrierefreien bzw. -reduzierten Wohnraum zuständig gefühlt. Versuche des Disability Mainstreaming sind demzufolge insbesondere durch die außerparlamentarischen Interessenvertretungen wahrgenommen worden.

Eine Ausnahme bilden zwei Kleine Anfragen aus dem Jahr 2016. Diese wurden ebenfalls von der SPD eingereicht, dieses Mal unter Federführung der gesundheits- und pflegepolitischen Sprecherin. Zur Berücksichtigung der Barrierefreiheit in der Bauordnung verweisen die Abgeordneten auf die UN-BRK und entsprechende Forderungen des VdK (Hessischer Landtag 2016b; Hessischer Landtag 2016c). Dieser oppositionelle Druck auf die Landesregierung ist im Sinne eines inkrementellen und politikfeldübergreifenden Prozesses zu interpretieren, erscheint angesichts der letztlich verabschiedeten Bauordnungsnovelle in seiner Wirkung aber begrenzt.

\section{Ministerialverwaltung}

Die dritte Akteursgruppe stellt die Ministerialverwaltung dar, wobei für das Bauordnungsrecht die entsprechenden Fachabteilungen im Wirtschaftsministerium zuständig sind (vgl. Kapitel 7.2.4). Durch ihre gesetzesvorbereitende Funktion kommt ihnen ein großer inhaltlicher Gestaltungsspielraum zu. Inwiefern wurde dieser im Sinne einer strategischen Interaktion oder eines bürokratischen Agenda-Settings in der No- 
vellierung der Hessischen Bauordnung genutzt (vgl. Kapitel 4.6.3)? Und spielten auch ministerielle Akteure aus dem Sozialressort eine Rolle?

Strategische Interaktion mithilfe außerparlamentarischer Interessen

Bereits in den Analysen zu außerparlamentarischen Interessen wurde ersichtlich, dass die Oberste Bauaufsicht im Vorhinein zur öffentlichen Anhörung Gespräche mit unterschiedlichen Interessenvertretungen geführt hat (vgl. Kapitel 7.2.5.1). In der Begründung zum Gesetzentwurf heißt es dazu: »Die kommunalen Spitzenverbände, die Architektenund Stadtplanerkammer Hessen, die Ingenieurkammer Hessen, die Handwerkskammer und die unteren Bauaufsichtsbehörden waren bereits bei der Vorbereitung des Entwurfs der Novelle eingebunden « (Hessischer Landtag 2017d: 2). Es konnte allerdings nachgewiesen werden, dass auch Behindertenverbände vorab die Möglichkeit bekamen, einen frühen Gesetzentwurf mit der Obersten Bauaufsicht zu besprechen. Hier nutzt die Fachabteilung ihr Potential zur strategischen Interaktion, indem sie unterschiedliche Interessen bereits bei der Erarbeitung des Gesetzentwurfes konsultiert und versucht, einen Ausgleich zwischen ihnen zu schaffen. Die Änderungen im Gesetzentwurf im Vergleich zur vorherigen Bauordnung sind letztlich ein Ergebnis dieser Gespräche.

Diese Prozesse versinnbildlichen, dass die Ministerialverwaltung zwar je als Expertin in ihrem Regelungsbereich gelten kann, aber auf fachliche Expertise aus der Praxis dennoch unbedingt angewiesen ist. Ein Sachverständiger für barrierefreies Planen, der auch in der Interessenvertretung von Menschen mit Behinderungen aktiv ist, kritisiert daran:

»In der Obersten Bauaufsicht sitzen Leute, die haben noch nie gebaut. Die lassen sich quasi von anderen Leuten erklären, wie die Wirklichkeit ist. Und dabei geraten sie an die extrem einflussreichen Interessenvertreter der Architektenverbände und der [...] Wohnungsbauindustrie. [...] [D]ie dümmste (lacht) Änderung der Hessischen Bauordnung ist, dass sie die Türbreiten auf $80 \mathrm{~cm}$ begrenzt haben. Und ich weiß, dass die Oberste Bauaufsicht das im blöden Clauben getan hat, sie machen damit das Bauen billiger. [...] Die Wohnungsbauverbände lachen darüber, weil, die kennen die Preise. Die wissen: eine 9oer-Tür ist heute nicht mehr teurer als eine 80er-Tür« (IP 46: 61ff.).

An dieser Stelle zeigt sich, wie essentiell das Berücksichtigen und Abwägen möglichst vieler unterschiedlicher Interessen ist. Diese umfassende Berücksichtigung wird jedoch dadurch erschwert, dass inzwischen zahlreiche Spezialinteressen Eingang in das Bauordnungsrecht finden - die Barrierefreiheit ist dabei lediglich eines von vielen. Hier scheint es, als orientiere sich die Oberste Bauaufsicht stärker an den einschlägigen Akteuren der Wohnungs- und Bauwirtschaft. Dies ist zur Reduzierung der Komplexität sinnvoll, erschwert es aber unterschiedlichen Zusatzbedarfen, Gehör zu finden.

Die Allianz für Wohnen wurde laut einem Allianz-Mitglied in die konkrete Bauordnungsnovellierung nicht eingebunden (IP 12: 18). Hierzu erklärt ein Vertreter aus dem Wirtschaftsministerium, die Allianz sei eher für die Entwicklung einer langfristig-strategischen Wohnungspolitik zuständig. Konkrete Gesetzesvorhaben wiederum würden über die einschlägigen Konsultationsverfahren der je betroffenen bzw. beteiligten Interessengruppen beratschlagt (IP 57: 37). 
Koordination und zweckrationale Interessen der Ministerialverwaltung

Auch eine Beteiligung des Sozialressorts ließ sich nicht nachweisen. Laut einem oppositionellen wohnungsbaupolitischen Sprecher scheiterten solche koordinierten Handlungsweisen an der Ressortlogik: »Also, wenn es wirklich um Bauordnungen geht, um die Normensetzung, wird sich das Bauministerium [...] nicht reinreden lassen (IP 50: 14, vgl. auch IP 14: 68ff.). Unter dem Erklärungsfaktor »Institutionen« ist zudem bereits der Normprüfungsleitfaden erörtert worden, welcher seit 2016 alle Gesetzesvorhaben und Verordnungen auf eine Konformität mit der UN-BRK überprüft (vgl. Kapitel 7.2.4). So heißt es im Gesetzentwurf: "Das Gesetz wurde am Maßstab der UN-Behindertenrechtskonvention überprüft. Es bestand kein Änderungsbedarf « (Hessischer Landtag 2017d: S. 5). Der in den späteren Stellungnahmen von den Behinderten- und Sozialverbänden teils so deutlich kritisierte Entwurf war aus Ministeriumssicht also konform mit der UN-BRK. Allerdings ist nicht transparent, ob das Referat zur Umsetzung der UN-BRK oder die Oberste Bauaufsicht für die Prüfung zuständig waren (IP 46: 121; Hessischer Landtag 2018a: CBF: 43; Hessischer Landtag 2018g: 341). An dieser Stelle zeigen sich die praktischen Herausforderungen bei der Umsetzung des Disability Mainstreaming. Die Ministerien verfügen über große Handlungsspielräume, die im nicht-öffentlichen Raum ausgeführt werden. Hier arbeiten Sozial- und Wirtschaftsministerium zusammen, da sie gemeinsam ihre als vertraulich eingestufte Arbeit vor äußeren Einblicken schützen.

Dieses zweckrationale Interesse wird noch durch ein weiteres Interesse ergänzt. So erklärt ein oppositioneller wohnungspolitischer Sprecher die Ministerialverwaltung insgesamt stärker am Status Quo denn an Veränderung interessiert. Er begründet das mit der langjährigen Arbeit der jeweiligen Fachabteilungen und dem für Veränderung notwendigen Eingeständnis, dass andere Bundesländer bessere Regelungen entwickelt hätten: »Auch als Abgeordneter [...] da brauchst du einen breiten Rücken, sich gegen die Beamten durchzusetzen [...]. Das sind Beamte, die sitzen seit Jahrzehnten auf derselben Stelle und machen ihren Job. Und die müssten ja immer ihre eigene Arbeit infrage stellen « (IP 50: 8ff.). Hier zeigen sich Pfadabhängigkeiten von in der Vergangenheit getroffenen Entscheidungen, die eine Kursänderung weniger wahrscheinlich werden lassen. An dieser Stelle ist das Zusammenspiel und die Machtrelation zwischen an Veränderung interessierten parteipolitischen Akteuren und der Ministerialverwaltung ausschlaggebend für den Ausgang der politischen Prozesse (vgl. Kapitel 4.6.3).

\section{Der Bauvorlagenerlass (»Barrierefrei-Konzept «) als bürokratisches Agenda-Setting?}

Zur Rolle der Ministerialverwaltung soll abschließend eine Neuerung erläutert werden, die mit der Novellierung der Hessischen Bauordnung 2018 einherging und von der Obersten Bauaufsicht aufgegriffen worden ist. Es handelt sich um das BarrierefreiKonzept, das als eine Art Checkliste zur Überprüfung der barrierefreien Vorgaben im Baugenehmigungsprozess fungiert (vgl. Kapitel 7.2.1). Die Einführung dieses Konzept hat sich dem politischen Diskurs weitgehend entzogen, wird aber von Akteuren aus der Praxis als wichtig in der Umsetzung des barrierefreien Bauens beschrieben und etwa in Sachsen-Anhalt auch von Behindertenverbänden eingefordert (IP 52: 8ff.; IP 54: 23).

In den Anhörungen zur Bauordnungs-Novelle haben die Bundesfachstelle Barrierefreiheit und der CBF die Einführung eines solchen Konzepts angeregt (Hessischer 
Landtag 2018g: 339; Hessischer Landtag 2018h: 98). Das letztliche Barrierefrei-Konzept wurde aber unterhalb des politischen Radars entwickelt und ist wohnungsbaupolitischen Sprecher*innen gar nicht bekannt (IP 49: 69; IP 53: 14). Damit handelt es sich hierbei um ein bürokratisches Agenda-Setting, oder besser: die Aufnahme derartiger Forderungen aus dem außerparlamentarischen Raum und die eigenständige Umsetzung durch die Ministerialverwaltung. Hierzu verweist eine Wohnberaterin auf die Rudolf Müller Mediengruppe, die über ihr Geschäftsfeld »bfb barrierefrei bauen« verschiedenste Fachveranstaltungen zum Thema organisiert: »Und da war interessanterweise Frau XX vom Hessischen Ministerium für Wirtschaft, [...] die dieses Konzept wohl maßgeblich mitgestaltet hat. Die war bei dieser Veranstaltung, um dort was zu lernen. [...] Und danach wurde auch nochmal ein bisschen was dran geändert « (IP 54: 21). An dieser Stelle wird die Relevanz externer Expertise ersichtlich, die sich Akteure der Ministerialverwaltung einholen. Auch über Hessen hinaus verweisen Expert*innen zum barrierefreien Bauen im Übrigen auf den hessischen Bauvorlagenerlass (IP 29: 439; IP 56: 52). Insofern kann dieser durchaus als eine Stärkung des barrierefreien Bauens in einem der Bauordnung nachgelagerten Erlass gelten - maßgeblich gesteuert durch die Akteure der Ministerialverwaltung.

Fazit zu barrierefreien Regelungen im Bauordnungsrecht

Bei den außerparlamentarischen Interessengruppen zeigt sich eine Trennlinie in diejenigen, die sich für eine stärkere Barrierefreiheit in der Bauordnung einsetzen und diejenigen, die vor allem mit Kostensteigerungen dagegen argumentieren. Die Diskussion ist festgefahren: Die je unterschiedlichen Interessengruppen belegen ihre Positionen mit der für sie stimmenden fachlichen Expertise. Verkompliziert wird der politische Prozess noch dadurch, dass Barrierefreiheit in der Bauordnung neben dem einschlägigen $\$ 54$ eine Vielzahl weiterer Paragraphen tangiert (vgl. Abbildung 31).

Abbildung 31: Von baulicher Barrierefreiheit berührte Paragraphen der HBO (eigene Darstellung)

Barrierefreiheit in der Hessischen Bauordnung

- $\int 2$ Begriffe

- $\int 36$ Erster und zweiter Rettungsweg

- $\$ 37$ Treppen

- 542 Aufzüge

- $\$ 51$ Wohnungen

- $\$ 54$ Barrierefreies Bauen

Die parteipolitischen Akteure wiederum beanspruchen alle für sich, eine Verbesserung des barrierefreien Bauens anzustreben. Diese Verbesserung interpretieren die Regierungsfraktionen CDU und Bündnis 90/Die Grünen allerdings anders als die SPD und DIE LINKE. Die Oberste Bauaufsicht tritt indessen als Black Box auf, hier kommt die empirische Analyse zu einem ambivalenten Ergebnis: Einerseits orientiert sich die Ministerialverwaltung stark an einschlägigen Akteuren der Wohnungs- und Bauwirtschaft, sodass es Veränderungsinteressen aus der Inklusionspolitik schwer haben. 
Auch die intransparente Normenprüfung zur Konformität der Bauordnungsnovelle mit der UN-BRK ist kein Musterbeispiel für gelingendes Disability Mainstreaming. Andererseits kann der Obersten Bauaufsicht für den nachgelagerten Bauvorlagenerlass (»Barrierefrei-Konzept«) eine aktive Veränderungsrolle unterstellt werden.

\subsubsection{Förderprogramme}

Für die Wohnraumförderung zum barrierefreien bzw. -reduzierten Wohnraum wurde bereits herausgearbeitet, dass die hessische WIBank über eine Vielzahl an Programmen verfügt, die entweder entsprechend ausgestatteten Wohnraum oder die Zielgruppen der Menschen mit Behinderungen bzw. älteren Menschen explizit mitdenkt (vgl. Kapitel 7.2.1). Die Wohnraumförderung ist dabei über die Veröffentlichung von Richtlinien organisiert und entzieht sich somit dem parlamentarischen Raum. Folglich bietet dieser Steuerungsbereich eine interessante Ergänzung zur parlamentarisch ausgetragenen Bauordnungsnovellierung. Welche Rolle kommt den außerparlamentarischen Interessen der Angebots- und Nachfrageseite nach Wohnraum in der Wohnraumförderung $\mathrm{zu}$ ? Inwieweit sind parteipolitische Akteure involviert? Und wie erfolgt die Umsetzung allgemeiner politischer Zielvorgaben in konkrete Richtlinien über die Ministerialverwaltung?

\section{Außerparlamentarische Interessen}

Die Wohnungs- und Bauwirtschaft ist die zentrale Adressatin der Wohnraumförderung. Demzufolge überrascht es nicht, dass diese in die Entwicklung neuer sowie die Überarbeitung bestehender Richtlinien eingebunden wird. Insbesondere der Verband der Südwestdeutschen Wohnungswirtschaft (VdW) wird diesbezüglich von Gesprächspartner*innen aus der WIBank genannt (IP 10: 48; IP 17: 49, 59). In der kommunalen Mietwohnraumförderung wird indessen stärker direkt mit den privaten Investor*innen der Bauwirtschaft zusammengearbeitet: »Genau, wir haben es direkt mit den Bauunternehmen gemacht, die selber bauen (IP 51: 10ff.). In beiden Fällen geht es aber darum, die letztlichen Programmnutzer*innen frühzeitig in die Programmentwicklung einzubeziehen, damit die aufgelegte Förderung am Ende auch genutzt wird. So ist die Wohnraumförderung laut einem Gesprächspartner aus der Wohnungs- und Bauwirtschaft denn auch für sie als Verband »einer der wichtigsten Bereiche« (IP 12: 38). Beispielsweise haben Wirtschaftsministerium und WIBank der Wohnungswirtschaft im Vorfeld die geplante Richtlinie zur Mietwohnraumförderung vorgestellt und auch nach der Veröffentlichung noch einmal gemeinsam diskutiert. Die Unternehmen konnten Stellung nehmen und erläutern, welche Konditionen aus ihrer Sicht noch verbesserungswürdig seien (ebenda: $38 \mathrm{ff}$.)

Das Interesse der Wohnungs- und Bauwirtschaft liegt in einer für sie attraktiven Ausgestaltung der Förderkonditionen (IP 17: 55ff.). So erschweren Belegungsbindungen für bestimmte Zielgruppen die Vermietung, und Zuschussförderungen sind naturgemäß attraktiver als Darlehen. Barrierefreiheit als Förderthema oder gar als verbindliche Fördervoraussetzung wurde aber etwa in der kommunalen Wohnraumförderung nur randständig erwogen. Der Fokus läge klar auf bezahlbarem Wohnen und so wären verbindliche barrierefreie Vorgaben »im politischen Diskurs auch mit den Investoren nicht 
durchsetzbar (IP 52: 93, vgl. auch IP 51: 15ff.). Auf Landesebene wird die strategische Ausrichtung der Wohnraumförderung in der Allianz für Wohnen diskutiert (IP 48: 38). Die Arbeitsgruppe 1 der Allianz hat sich in den Jahren 2015/16 mit Bedarfen, Zielgruppen und Modellen beschäftigt und vorgeschlagen, Wohnraumbedarfe nach Zielgruppen und Wohnformen zu identifizieren und zu quantifizieren (HMUKLV 2016a: 10ff.). Hier geht es also zunächst um eine Bestandsaufnahme, die konkreten politischen Maßnahmen vorgelagert ist. Im 12-Punkte-Plan der Allianz des Jahres 2019 zeigt sich außerdem schon im Namen »Bezahlbaren Wohnraum schaffen - bestehenden sichern« die Schwerpunktsetzung auf Bezahlbarkeit (HMWEVW 2019a: 3). Punkt 6 »Selbstbestimmt wohnen - Barrierefreiheit fördern« beschreibt Modellprojekte in diesem Bereich und setzt sich für die Förderung von gemeinschaftlichen Wohnformen ein. Ein Schwerpunkt liegt auf dem altersgerechten Umbau und der Anpassung bestehenden Wohnraums - hier findet sich die Empfehlung für ein entsprechendes Zuschussprogramm für den Mietwohnraum (HMWEVW 2019a: 7). Nicht thematisiert werden indessen barrierefreie Kriterien für die Neubauförderung, ebenso wenig eine Steuerung über das regulative Bauordnungsrecht.

Freiwillige Zusatzförderungen, wie sie auch die Programme der WIBank vorsehen, stellten insgesamt einen Anreiz dar und würden vom Markt angenommen (IP 52: 93). Insofern kritisiert ein Interviewpartner aus der Wohnungs- und Bauwirtschaft, dass mit der letzten Richtlinien-Überarbeitung des Jahres 2018 die Mehrförderung für barrierefreie und eingeschränkt mit dem Rollstuhl nutzbare Wohnungen entfallen ist (IP 12: 12, vgl. Kapitel 7.2.1). Zudem verweist er auf die bereits von der Allianz formulierte Empfehlung, das Zuschussprogramm zum behindertengerechten Umbau von selbstgenutztem Wohnraum auf den Mietwohnraum auszuweiten: "Das war eine Forderung, die wir auch vor der Landtagswahl aufgestellt haben [...]. Wurde aber nicht erfüllt, ist nicht im Koalitionsvertrag. Ist aber auch [...] sage ich mal, keine unserer Top-Forderungen « (IP 12: 46). Laut WIBank habe es früher einmal eine entsprechende, aber wenig genutzte Förderung gegeben (IP 17: 55). Diese als Pfadabhängigkeit nachwirkende Erfahrung sorgt dafür, dass es heute schwierig ist, ein solches Programm wiedereinzuführen. Eingeführt wurde stattdessen im Jahr 2018 eine zusätzliche Förderung für Aufzüge, die ebenfalls auf Anregungen aus der Wohnungs- und Bauwirtschaft zurückzuführen sei (IP 17: 97; IP 57: 13ff.; HMUKLV 2018: 10).

Anders als die Angebotsseite tritt die Nachfrageseite nach Wohnraum nicht als aktiver Player in der Wohnraumförderung auf. Zwar erklärt eine Gesprächspartnerin aus der WIBank, dass Sozial- oder Behindertenverbände bei speziellen Projekten wie Frauenhäusern oder Seniorenwohnanlagen beteiligt werden könnten. Aber insgesamt wären diese Interessengruppen wenig präsent: »Weiß ich nicht, ob das Land die einlädt ... es gibt ja noch das Sozialministerium, was die treiben-also, die haben mit dem Wohnungsbau keine Berührung, ganz selten « (IP 17: 66ff.). Diese Akteure konzentrieren sich scheinbar stärker auf das Bauordnungsrecht als verbindlichen regulativen Rahmen zur Barrierefreiheit. Ein Interessenvertreter von Menschen mit Behinderungen erklärt wiederum für die Angebotsseite von Wohnraum genau umgekehrt eine Präferenz der ökonomischen Förderung: Statt verbindlicher Vorgaben wäre das Ziel der Bauwirtschaft die Subventionierung der Barrierefreiheit über die Landesförderung (IP 46: 61ff.). Hier bestehen je 
nach Akteursgruppe unterschiedliche präferierte Policy-Mixes zum barrierefreien bzw. -reduzierten Wohnraum (vgl. ideologische Filter, Kapitel 4.2.1).

\section{Parteipolitik}

Wie eingangs skizziert, verabschiedet der Landtag mit dem Wohnraumfördergesetz eine Leitlinie, im Rahmen derer die ministeriellen Fachabteilungen die konkreten Richtlinien erarbeiten (vgl. Kapitel 7.2.1). Generell sind Förderprogramme wenig umstritten und werden mit Blick auf die Wahlprogramme als »Unterstützung« oder »Förderung« von barrierefreiem, seniorengerechtem oder ähnlich beschriebenem Wohnraum von allen Parteien gefordert. Insbesondere durch die angespannten Wohnungsmärkte im Rhein-Main-Gebiet seien ökonomische Förderungen "politisch getrieben«, um auf entsprechende Wählerwünsche einzugehen: »Wohnungsbau ist halt auch so eine Sache [...]. Es wird ganz viel produziert und dann wird es ganz rapide runtergefahren und wenn dann auf einmal wieder der Bedarfbesteht - der nicht bestünde, wenn es durchgehend wäre-dann wird wieder wie wild produziert « (IP 17: 45ff.). Dies entspricht klar einem Vote-Seeking-Motiv und wird von verschiedenen Interviewpartner*innen bestätigt (IP 48: 46; IP 50: 16).

Die konkrete Ausgestaltung der Förderprogramme über politische Zielvorgaben hinaus findet wie gezeigt jedoch nicht im engeren politischen Raum statt (IP 19: 25). Oppositionsparteien können deshalb lediglich im Rahmen von parlamentarischen Initiativen auf Aspekte hinweisen, die aus ihrer Perspektive bislang unterbelichtet oder $\mathrm{zu}$ wenig gefördert würden. So kritisiert die SPD an einer Regierungserklärung von CDU-Sozialminister Grüttner im Jahr 2017 zum Thema »Neuer Blick aufs Alter« die Fokussierung der Landesregierung auf Modellförderungen. Da nicht alle Menschen in Mehrgenerationen-Projekten wohnen wollten, regt die SPD an, die allgemeine Wohnraumförderung stärker auch auf die Bedarfe von älteren Menschen auszurichten (Hessischer Landtag 2017a: 7482, vgl. IP 49: 56ff.). Über solche Anstrengungen kann die Opposition Druck auf die Landesregierung ausüben. Da allerdings barrierefreier bzw. -reduzierter Wohnraum neben der allgemeinen Bezahlbarkeitsdebatte wenig prominent diskutiert wird, ist die parteipolitische Profilierung hier eher gering (vgl. Problemstrukturen). Umso wichtiger sind mutmaßlich die Akteure aus der Ministerialverwaltung, denen insbesondere in Low-Level Settings mit wenig öffentlicher Aufmerksamkeit eine große Gestaltungsfähigkeit zugeschrieben wird.

\section{Ministerialverwaltung}

Die jeweiligen Fachressorts im für Wohnraumförderung zuständigen Ministerium sind bei der Ausgestaltung von Förderrichtlinien der zentrale Akteur. Diese sitzen seit 2019 im Wirtschaftsministerium, zuvor im Umweltministerium (vgl. Kapitel 7.2.4). Neben dem bürokratischen Agenda-Setting und der strategischen Interaktion soll auch geprüft werden, inwieweit eine Koordination zwischen den Fachabteilungen für Wohnraumförderung und dem Sozialministerium als Vertretung von Menschen mit Behinderungen und älteren Menschen stattfindet.

Durch die allgemeinen politischen Leitlinien und die oft jahrelangen Arbeitsbeziehungen zwischen Ministerium, WIBank und Interessengruppen betonen mehrere Interviewpartner*innen die zentrale Rolle der Ministerialverwaltung in der Wohnraum- 
förderung (IP 10: 42ff., 70ff.; IP 17: 48; IP 19: 26, 72ff.; IP 52: 48ff.). Dies spricht im Rahmen der bestehenden Vorgaben - etwa über den Koalitionsvertrag oder das Wohnraumfördergesetz - für ein großes Potential zur strategischen Interaktion. Ein wohnungsbaupolitischer Sprecher erklärt:

»Das Cesetz zur Wohnraumförderung ist ein Rahmengesetz [...]. Da der Cesetzgeber denen [den ministeriellen Akteuren, Anm. der Autorin] jetzt einen breiten Korridor eingerichtet hat, was die alles machen können, setzt also das Ministerium selber den Schwerpunkt, was denn tatsächlich an Wohnen gefördert wird« (IP 50: 14).

Über Rückmeldungen aus der Wohnungswirtschaft und der WIBank wird die Ausgestaltung der Richtlinien auch von einem Mitglied einer Regierungsfraktion als »Verwaltungshandeln « beschrieben (IP 53: 29, vgl. auch IP 10: 48; IP 17: 49).

Diese Ausgestaltung geschieht in Hessen über eine Ressortabstimmung und eine nichtöffentliche Verbändeanhörung. Zwar sei eine solche Anhörung in der Gemeinsamen Geschäftsordnung der Staatskanzlei, der Ministerien des Landes Hessen sowie der Landesvertretung Berlin nicht verbindlich vorgeschrieben. Um aber die spätere Passfähigkeit der Förderprogramme mit den Programmnutzer*innen zu koordinieren, würde die Wohnungs- und Bauwirtschaft frühzeitig einbezogen. Abschließend entscheide der/die Minister*in, ob die geplanten Richtlinien der politischen Leitlinie entsprechen (IP 57: 4ff., 43). Insgesamt bescheinigt aber ein Gesprächspartner aus dem Wirtschaftsministerium der Fachabteilung in diesem Prozedere einen großen Handlungsspielraum: »Es hängt an Ihrer eigenen Person: Habe ich Lust, mich dann vielleicht doch mit den Verbänden mal zusammenzusetzen, im Vorhinein, und mit denen zu sprechen: >Was sind denn nochmal konkret eure Forderungen? « und >Guckt mal, wir haben uns das und das ausgedacht, könnt ihr damit leben?« (IP 57: 29). Insbesondere gilt es, die verschiedenen Interessen von Mieterschutzverbänden sowie Wohnungs- und Bauwirtschaft durch ein stetes Telefonieren und Aushandeln auszutarieren (IP 57:36f.). Dabei stellt die von der Landesregierung eingerichtete Allianz für Wohnen eine zentrale bündelnde Instanz dar. So wurde das bereits erläuterte 12-Punkte-Programm unter ministerieller Leitung ausgearbeitet. Zwar sei ein solches Programm nicht rechtlich bindend, erzeuge aber durch seine breite Beteiligung einen spürbaren Handlungsdruck und müsse sich dadurch letztlich auch in der Ausgestaltung der Förderprogramme wiederfinden (IP 57: 29). Hier geht es also nicht primär um wertrationales Handeln der ministeriellen Akteure, sondern darum, welche außerparlamentarischen Interessen von der Ministerialverwaltung angehört und berücksichtigt werden. Dies sind insbesondere die einschlägigen wohnungsund bauwirtschaftlichen Akteure und damit weniger die Vertretungen von Spezialinteressen wie der Barrierefreiheit.

Diese Einschätzung spiegelt sich darin wider, inwieweit das Sozialministerium an der Richtlinien-Erstellung und -Überarbeitung beteiligt ist: $\gg A l s o$, wir binden das Sozialministerium nicht ein, nein. [...] Also, das ist jetzt ein Thema, das sind unsere Gelder. [...] Und bei uns ist es auch nicht ordinäre Aufgabe, barrierefreien Wohnraum herzustellen« (IP 57: 9ff.). Weitere Zusatzinteressen würden beständig von den jeweiligen Interessenvertretungen eingebracht - energetische Aspekte insbesondere in der letzten Legislaturperiode, in der die Wohnraumförderung im Umweltministerium verortet war. Der Schwerpunkt der Wohnraumförderung wird indessen klar in der Bereitstellung von bezahlbarem Wohn- 
raum gesehen, weniger in der Abdeckung weiterer mit der Wohnungspolitik verbundener Belange (IP 57: 13; vgl. auch IP 50: 14).

Umgekehrt weisen Zusatzinteressen, sobald sie es einmal in die Förderkulisse geschafft haben, eine große Pfadabhängigkeit auf. Das Zuschussprogramm für den behindertengerechten Umbau von selbstgenutztem Wohnraum bspw. besteht seit den frühen 2000er Jahren und schon zuvor wurden ähnliche Fördertatbestände über andere Programme gefördert (IP 17: 9ff., 101). Ein Gesprächspartner aus der WIBank erklärt: »Und das ist denke ich mal ein Evergreen, da würde niemand drangehen und das komplett streichen. Also, das läuft sozusagen immer mit. [...] Und dann bedürfte es schon einer erheblichen Änderung der politischen Vorgaben, da etwas dran zu ändern (IP 10: 74ff.). Vielmehr fand in diesem Programm nach 2015 sogar eine Verdopplung der Mittel statt (vgl. Kapitel 7.2.1). Hier koppelt sich das Ministerium mit den Kommunen und der WIBank rück: Wenn ein Programm stark nachgefragt wird und der Haushalt es erlaubt, erfolgt eine Aufstockung in diesem Fall ohne großen politischen Prozess, da das besprochene Programm im Vergleich zur gesamten sozialen Wohnraumförderung mit ein bzw. zwei Millionen Euro pro Jahr über ein geringes Finanzvolumen verfügt (IP 10: 36; IP 17: 44ff.).

Jedoch können Förderbestandteile zur Barrierefreiheit auch zurückgenommen werden, wird doch seit Sommer 2018 der vorherige Zuschuss für barrierefreie und eingeschränkt mit dem Rollstuhl nutzbare Wohnungen nicht mehr gewährt (vgl. Kapitel 7.2.1). Hier gab es immer wieder »sehr, sehr große Abstimmungsschwierigkeiten zwischen der Förderbank [...] und den Investoren, sodass wir gesagt haben: Nein, das streichen wir komplett « (IP 57: 13ff.). An dieser Stelle wird auf die Hessische Bauordnung verwiesen, nach der zu einem gewissen Anteil Wohnungen nach DIN 18040-2 ohne R-Anforderung herzurichten seien. Entsprechend sei die zusätzliche Förderung nicht mehr notwendig (ebenda, IP 17: 13). Hier argumentiert das Ministerium mit einer interessanten Verschiebung von der Wohnraumförderung zum Bauordnungsrecht (vgl. Kapitel 4.2.1 zum Policy-Mix).

Insgesamt ist die Ministerialverwaltung in der Wohnraumförderung also ein mächtiger Akteur. Sie nutzt ihre Handlungsspielräume zur strategischen Interaktion im Zusammenspiel mit der WIBank und außerparlamentarischen Interessen. Eine Gesprächspartnerin aus der kommunalen Wohnraumförderung berichtet zudem von Formen des bürokratischen Agenda-Settings: »Also, wir haben ja diese Punkte mit der Barrierefreiheit und Co, haben wir in unseren Richtlinien mit drin. [...] aber das kommt eher von uns, das kommt eher von Verwaltungsseite aus [...]. Es ist ein Thema, was jetzt nicht an erster Stelle bei den Entscheidungsträgern steht « (IP 52: 48ff.). In derselben Stadt sei auch das Sozialdezernat über eine Stabstelle für Menschen mit Behinderungen an der Überarbeitung von Richtlinien beteiligt (IP 51: 15ff.). Je nach föderaler Ebene und Zuständigkeit variiert also, mit welchem Selbstverständnis und mit welchen weiteren Beteiligungen die Erstellung und Überarbeitung von Richtlinien erfolgt.

\section{Fazit Förderprogramme}

Zusammenfassend ergänzt die Wohnraumförderung in Hessen den Policy-Mix zum barrierefreien bzw. -reduzierten Wohnraum, fällt aber in ihrer politischen Wahrnehmung deutlich hinter dem Bauordnungsrecht zurück. Laut einem Gesprächspartner aus der WIBank ist die Barrierefreiheit »jetzt nicht so das zentrale Thema. Ist es im Mo- 
ment nicht und war es auch in der Vergangenheit nicht. Im Moment wird alles überrollt durch den Wohnungsmangel in den Ballungszentren « (IP 10: 22). Der Wohnungs- und Bauwirtschaft als Angebotsseite von Wohnraum konnte zwar eine starke Rolle in der Erstellung und Überarbeitung von Richtlinien bescheinigt werden. Hierbei spielt das barrierefreie Bauen bzw. das barrierereduzierende Umbauen aber nur eine untergeordnete Rolle und die Nachfrageseite nach Wohnraum ist in diese Prozesse nach den vorliegenden Erkenntnissen nicht eingebunden. Die Landtagsfraktionen beschränken sich auf das Setzen politischer Leitlinien im Rahmen des Koalitionsvertrages oder des Wohnraumfördergesetzes, während die konkrete Ausgestaltung den ministeriellen Fachabteilungen obliegt. Diese erfüllen ihre Aufgabe im Zusammenspiel mit der WIBank und den Interessenvertretungen, insbesondere der Wohnungs- und Bauwirtschaft.

\subsubsection{Wohnberatungsstellen bzw. Kompetenzzentrum für Barrierefreiheit}

Die Wohnberatung zur Wohnungsanpassung ergänzt neben dem Bauordnungsrecht und der Wohnraumförderung den Policy-Mix zum barrierefreien bzw. -reduzierten Wohnraum. Die Entwicklung der Hessischen Fachstelle für Wohnberatung (HFW) wurde bereits unter »Instrumente und Instrumenten-Alternativen« dargestellt (vgl. Kapitel 7.2.1). Seit ihrer Einrichtung im Jahr 2002 besteht die HFW in mehr oder weniger unveränderter Form, was auf ausgeprägte Pfadabhängigkeiten in diesem Bereich hindeutet. Sie ist politisch unumstritten und als informationelles Angebot für ältere Menschen mit Umbaubedarf verweisen politische Entscheider"innen auf die HFW (IP 19: 19ff.). Weder von der Angebotsseite noch von der Nachfrageseite nach Wohnraum wird eine Ausweitung oder Änderung der politischen Steuerung im Bereich der Wohnberatung zur Wohnungsanpassung gefordert. Auch die Fachstelle selbst versteht sich nicht als Interessenvertretung der Wohnberater*innen, sondern stärker als Dienstleisterin des Sozialministeriums (IP 16: 30ff., 47ff., 73). Eine hessische Wohnberaterin merkt da$\mathrm{zu}$ an, dass eine politische Arbeit naturgemäß schwierig sei, wenn die Finanzierung vom Land abhänge. Zudem fehlt dieser Interviewpartnerin »eine klare Haltung [...]. Da ist mir nicht ganz klar, welche Ziele das Land verfolgt, mit der Hessischen Fachstelle für Wohnberatung« (IP 54: 37ff.). Hier sei nicht eindeutig, welche Aufgabe die Vernetzungstreffen hätten - insbesondere, inwieweit diese zur stärkeren Artikulation der Interessen der Wohnberatungen an die Landesregierung genutzt werden könnten (ebenda). Politische Prozesse zur weiteren Entwicklung der Fachstelle sind also nicht nachweisbar.

Wie in Sachsen-Anhalt wird allerdings auch in Hessen die Einrichtung einer zentralen Fachstelle für Barrierefreiheit diskutiert. Bereits der Hessische Aktionsplan zur Umsetzung der UN-BRK des Jahres 2012 enthielt im Bereich »Barrierefreies Bauen/Wohnen« diese Forderung (HMSI 2012: 48) und Interessenvertretungen von Menschen mit Behinderungen fordern entsprechend seit Jahren eine solche Fachstelle bzw. ein Kompetenzzentrum. Ein Mitglied des Landesbehindertenrats berichtet: »Und das ist tatsächlich Teil des Koalitionsabkommens geworden [...]. Aber bei der nächstmöglichen Gelegenheit wollen wir auch in den Kontakt mit dem Minister gehen [...]. Das ist eine Chance, die wir dann auch nutzen wollen« (IP 8: 93). In der Tat findet sich im Wahlprogramm von Bündnis 90/Die Grünen zu den Landtagswahlen 2018 und später im schwarz-grünen Koalitionsvertrag ein Kompetenzzentrum Barrierefreiheit zur Unterstützung von Kommunen, Vereinen, Ver- 
bänden und Behörden (BÜNDNIS 90/DIE GRÜNEN Hessen 2018: 110; Landesregierung Hessen 2019: 23). Was genau die Aufgabe einer solchen Stelle und was ihr Verhältnis zur HFW wäre, ist bislang nicht geklärt. Hier wiederum treten die Behindertenverbände als Veränderungsinteressen auf, parlamentarisch unterstützt durch Bündnis 9o/Die Grünen. Die Zuständigkeit liegt im Sozialressort, sodass Querverbindungen zum Bauordnungsrecht und zur Wohnraumförderung wiederum über Formen des Disability Mainstreamings adressiert werden müssten (vgl. Kapitel 4.5.1).

\subsubsection{5 Übergeordnete Ressourcen und Strategien}

Bislang wurden die politischen Prozesse zum Bauordnungsrecht, zur Wohnraumförderung und zu informationellen Angeboten im Bereich des barrierefreien bzw. -reduzierten Wohnraums separat analysiert. Finden sich in diesen Prozessen übergeordnete Muster im Akteurshandeln? Wurde eingangs mit den übergeordneten Interessen als theoretischem Startpunkt begonnen, schließt das UnterKapitel zu »Akteuren und ihren Handlungen « mit den übergeordneten Ressourcen und Strategien. Dies erfolgt wiederum für den akteurstheoretischen Dreiklang aus außerparlamentarischen Interessen, Parteipolitik und Ministerialverwaltung.

\section{Außerparlamentarische Interessen}

Die Angebotsseite von Wohnraum ist in Hessen im Bauordnungsrecht und in der Wohnraumförderung ein aktiver politischer Player. Zur Durchsetzung ihrer Interessen kann die Wohnungs- und Bauwirtschaft dabei auf strukturelle und finanzielle Machtressourcen zurückgreifen (vgl. Kapitel 4.6.1). Ihre strukturelle Macht besteht darin, dass sie zur Herstellung von Wohnraum im Allgemeinen und von barrierefreiem bzw. -reduziertem Wohnraum im Speziellen gebraucht wird. Die politischen Entscheider*innen sind zur Umsetzung ihrer politischen Ziele also auf die Wohnungs- und Bauwirtschaft angewiesen, was deren Verhandlungsposition stärkt. Ferner verfügen kommunale Wohnungsunternehmen über eine große Nähe zu kommunalpolitischen Entscheider*innen, was die Interessenartikulation erleichtert (IP 12: 78). Und zudem besitzen die an der Bereitstellung von Wohnraum beteiligten Akteure Expertise zu Fragen des Bauens und Umbauens, worauf sie in den politischen Prozessen wiederholt rekurrieren (IP 48: 68). Eine finanzielle Macht wiederum liegt darin, dass die Verbände der Wohnungs- und Bauwirtschaft durch ihre Mitgliedsunternehmen über eine relativ gesehen größere Mittelausstattung verfügen als die Nachfrageseite nach Wohnraum. Eine Interviewpartnerin erklärt: » Als Wohnungsverband, [...] der Unternehmen vertritt, die gewinnorientiert arbeiten, hat man schon [...] alleine über die finanziellen Mittel ganz andere Möglichkeiten, seine Interessen umzusetzen« (IP 20: 40ff., vgl. auch IP 7: 28). Das schlägt sich etwa darin nieder, inwieweit Verbände ehrenamtlich oder hauptamtlich ihre Interessen vertreten. Auf Basis dieser Ressourcen arbeitet die Angebotsseite eine glaubhafte Drohkulisse aus, nach der sie bei Verteuerungen des Wohnungsbaus durch regulative Vorgaben weniger Wohnraum zur Verfügung stellen kann. Ihre strukturelle Macht führt außerdem dazu, dass sie vom politisch-administrativen System bereits frühzeitig in die Politikformulierung eingebunden wird (IP 12: 20, 32). 
Die Nachfrageseite setzt sich insbesondere für eine stärkere Verankerung von Barrierefreiheit im Bauordnungsrecht ein, aber auch bei der geplanten Kompetenzstelle Barrierefreiheit treten Menschen mit Behinderungen als Veränderungsinteressen auf. Anders als die Angebotsseite von Wohnraum verfügen diese Akteure über keine strukturellen und weniger finanzielle Machtressourcen. Durch die schwach ausgeprägte Salienz von barrierefreiem bzw. -reduziertem Wohnraum ist auch die gesellschaftliche Macht in Form von gesellschaftlicher Unterstützung gering. Erschwerend hinzu kommt die Heterogenität von Behinderungen, die ein gemeinsames Auftreten mit einer Stimme hemmt (vgl. auch Problemstrukturen). Hierzu erklärt eine Interviewpartnerin: »Die Menschen mit Sehbehinderungen sind ganz anders draufals die Menschen mit Gehörlosigkeit. [...] Und da sind manche Fronten schon sehr verhärtet. Und das macht es dann manchmal auch nicht einfacher, als eine Gemeinschaft oder eine gemeinschaftliche Lobby dazustehen (IP 54: 57ff., vgl. auch IP 14: 46; IP 50: 32). Diese Zerrissenheit zeigt sich auch zwischen spezialisierten Behindertenverbänden und Sozialverbänden. Beispielhaft verfüge der VdK als großer Sozialverband einerseits über ein stärkeres politisches Gehör (IP 14: 44), andererseits beschreiben ihn Behindertenvertretungen als »konservativ« und kritisieren die Schwerpunktsetzungen der Petition zur Bauordnung: »[I]ch finde nicht, dass sie die wirklichen Probleme der Bauordnung ansprechen « (IP 8: 69; IP 46: 118).

Die Ressourcen der Nachfrageseite indizieren eine eher schwache Interessendurchsetzung, weshalb in Hessen mit dem/der Behindertenbeauftragten und dem Inklusionsbeirat korporatistische Strukturen entwickelt wurden, die die Verhandlungssituation der Menschen mit Behinderungen an anderer Stelle stärken könnten (vgl. Kapitel 7.2.4). Allerdings tritt die bisherige Behindertenbeauftragte in den politischen Prozessen zum Bauordnungsrecht und zur Wohnraumförderung nicht offensiv auf. Auf Nachfrage erklären Interviewpartner*innen aus dem politisch-administrativen System eher nachgeschoben, dass diese im Rahmen der Ressortanhörung auch eingebunden sei (IP 53: 37; IP 57: 5). Ein Interessenvertreter von Menschen mit Behinderungen beschreibt: "[D]ie Stelle der Landesbehindertenbeauftragten ist eben sehr von der Person geprägt, die Landesbehindertenbeauftragte ist (IP 46: 104). Durch eine Neubesetzung des Amtes im Frühjahr 2020 und eine nunmehr hauptamtliche Tätigkeit könnte sich die Rolle der Behindertenbeauftragten zukünftig indessen neu gestalten (Landesregierung Hessen 2019: 23).

Die Strategien sowohl der Angebots- als auch der Nachfrageseite wirken im Sinne eines inkrementellen Politstils, in dem die jeweiligen Interessen stetig und langfristig in das politisch-administrative System eingespeist werden (IP 8: 9, 21ff.; IP 20: 6, 62; IP 14: 76ff.; IP 54: 33). Dabei gelten parteipolitische Akteure ebenso wie die Ministerialverwaltung als Lobby-Adressat*innen - in beiden Fällen bestünden langjährige Netzwerke, auf die zur Interessenartikulation zurückgegriffen werden könnte (IP 12: 24, 64; IP 20: 24; IP 49: 51; IP 51: 44; IP 53: 21). Interessenkoalitionen von Angebots- und Nachfrageseite nach Wohnraum, die gemeinsame Positionen entwickeln, konnten dabei für Hessen nicht nachgewiesen werden (IP 12: 80; IP 20: 40). 


\section{Parteipolitik}

Die parteipolitischen Akteure greifen vielfach Interessen aus dem außerparlamentarischen Raum auf und transportieren diese in das politisch-administrative System. Dies ließ sich in Hessen für alle drei untersuchten Maßnahmen zeigen und belegt die Expertenrolle, die außerparlamentarische Interessen einnehmen und für ihre Interessenartikulation nutzen. Damit können sie die Positionen der parteipolitischen Akteure beeinflussen und in ihrer Argumentation stärken oder schwächen.

Generell stehen den Landtagsfraktionen zur Durchsetzung ihrer Interessen unterschiedliche Ressourcen zur Verfügung. Beginnend mit der Regierungsverantwortung verfügen die schwarz-grünen Regierungen der Kabinette Bouffier II und III über größere Handlungsspielräume als die oppositionellen Kräfte, müssen sich aber durch den Koalitionszwang zugleich intern abstimmen (IP 19: 39; IP 48: 46). Zudem beeinflussen der Ressortzuschnitt und die zuständigen Minister*innen maßgeblich die Ressourcen der einzelnen Regierungsfraktionen. Für den barrierefreien bzw. -reduzierten Wohnraum ist vor allem das für Wohnen und Bauen zuständige Ministerium relevant. Den jeweiligen Umwelt- und Wirtschaftsministerien (2014-19) bzw. dem Wirtschaftsministerium (2019-24) standen grüne Minister*innen vor, während das Sozialministerium im Jahr 2019 die Farbe von schwarz auf grün wechselte. Den Landtagsfraktionen wird dabei ein besserer Zugang zu den Ministerien nachgewiesen, die parteipolitisch dieselbe Färbung aufweisen. Durch die Regierungsanhörung findet jedoch insgesamt eine frühzeitige Einbindung der Regierungsfraktionen statt und auch in der Allianz für Wohnen sind ausschließlich die regierenden Fraktionen vertreten (IP 49: 21; IP 53: 19).

Die Opposition verfügt über diese Ressourcen nicht und muss ihren Positionen eher über Strategien des öffentlichen Drucks Gehör verschaffen (IP 19: 13; IP 50: 16). Insbesondere die SPD war in der Bauordnungsnovellierung aktiv, wozu die wohnungsbaupolitische Sprecherin erklärt: "So manche Forderung, die wir stellen, wird abgelehnt und findet sich dann in einem Regierungsentwurf wieder. [...] Unsere Rolle ist, glaube ich, den Scheinwerfer auf Probleme zu setzen, ja. Und irgendwann passiert dann doch was (IP 49: 56ff.). Hier zeigt sich ein Ansteckungseffekt, wobei die regierenden Kräfte teils zeitverzögert Positionen der Opposition aufgreifen (vgl. Kapitel 4.6.2). Diese Versuche des oppositionellen Agenda-Settings werden von der SPD auch über Kleine Anfragen zum altersgerechten Wohnraum und zu bedarfsgerechten Wohn-, Versorgungs- und Pflegestrukturen betrieben (Hessischer Landtag 2015b; Hessischer Landtag 2015c). In beiden Fällen war jedoch der Sozialminister Adressat der Kleinen Anfrage, nicht das damals für Wohnen und Bauen zuständige Umwelt- bzw. Wirtschaftsministerium. Auch zeigt sich hier die Breite des Disability Mainstreamings: Ebenfalls von der SPD wurden Anfragen zur Barrierefreiheit als Bestandteil im Architekturstudium gestellt sowie zu barrierefreien Studierendenwohnheimen (Hessischer Landtag 2016a; Hessischer Landtag 2020a: 5). Konkret für die Bauordnungsnovellierung des Jahres 2018 erscheint die SPD als diejenige Partei, die sich im parlamentarischen Raum am vehementesten für eine stärkere Verankerung der Barrierefreiheit eingesetzt hat. Hier darf indessen nicht vergessen werden, dass oppositionelle Kräfte leichter eine fordernde Rolle einnehmen können, wohingegen regierende Fraktionen stärker den Ausgleich verschiedenster Interessen berücksichtigen müssen. 
Ministerialverwaltung

Die ministeriellen Akteure aus den für Bauen und Wohnen bzw. Soziales zuständigen Ressorts dienen der Landesregierung offiziell als Entscheidungshelfer*innen ohne eigene wertrationale Interessen (vgl. Kapitel 4.6.3). Für das Bauordnungsrecht und die Wohnraumförderung konnte gezeigt werden, dass das Sozialministerium trotz seiner Zielgruppen von älteren Menschen und Menschen mit Behinderungen wenig in die politischen Prozesse eingebunden war. Versuche des Disability Mainstreaming über den Hessischen Aktionsplan zur Umsetzung der UN-BRK oder das Behindertengleichstellungsgesetz werden eher von außerparlamentarischen Veränderungsinteressen unternommen.

In den Ministerien selbst dominiert die Ressortlogik. Hier verfügt das Wirtschaftsbzw. vor 2019 zusätzlich das Umweltministerium über die zentralen Handlungsressourcen. Insbesondere für die Ausbalancierung der unterschiedlichen Interessen nimmt die Ministerialverwaltung in den öffentlichen Anhörungsverfahren zur Bauordnungsnovelle sowie in den nichtöffentlichen Anhörungen zur Wohnraumförderung eine wesentliche Rolle ein. Hier verfügen die Fachabteilungen über große Potentiale zur strategischen Interaktion, indem sie entscheiden, welchen Argumenten welches Gewicht zukommt und welche Akteure überhaupt angehört werden. In der Wohnraumförderung erscheint dieses Potential noch größer als im Bauordnungsrecht, da diese sich weitgehend dem parlamentarischen Prozess entzieht. Hierbei findet eine enge Kooperation einerseits mit der Landesförderbank WIBank und andererseits mit den Akteuren der Allianz für Wohnen statt.

Ein administratives Agenda-Setting, wo ministerielle Akteure selbst Themen auf die Tagesordnung setzen, wurde für den barrierefreien bzw. -reduzierten Wohnraum auf hessischer Landesebene nicht nachgewiesen (für die kommunale Wohnraumförderung bestand dies durchaus, vgl. Kapitel 4.2.5.3). Lediglich beim sogenannten BarrierefreiKonzept, dem Bauvorlagenerlass im Genehmigungsverfahren, schien die Fachabteilung als aktiver Veränderungsakteur auf. Gleichzeitig kam die Initialtätigkeit dazu aus dem außerparlamentarischen Raum.

\section{»Akteure und ihre Handlungen« in Hessen}

Das politische Augenmerk zum barrierefreien bzw. -reduzierten Wohnraum liegt in Hessen auf dem Bauordnungsrecht. Hier verhindert eine breite Koalition der Angebotsseite von Wohnraum eine weitere Verschärfung der barrierefreien Vorgaben, was in der Bauordnungsnovellierung des Jahres 2018 zu einer Streichung der Rollstuhlgerechtigkeit und der umstrittenen 20-Prozent-Regelung führt. Behinderten- und Sozialverbände kritisieren die Änderungen über das formelle Anhörungsverfahren hinaus - in Form einer VdK-Petition - als Verstoß gegen inklusionspolitische Zielsetzungen. Im parlamentarischen Raum unterstützen die oppositionelle SPD und DIE LINKE die Forderungen nach einer stärkeren Verankerung von Barrierefreiheit, wohingegen die schwarz-grüne Landesregierung ihrerseits Verbesserungen im Vergleich zur Bauordnung des Jahres 2011 hervorhebt. Die hessische Wohnraumförderung konzentriert sich auf preiswerten und schnellen Wohnungsbau, barrierefreie Kriterien im Neubau bzw. der barriereredu- 
zierende Bestandsumbau werden wenig diskutiert. Die Ministerialverwaltung orientiert sich in der Ausgestaltung der Förderrichtlinien zuvorderst an einschlägigen wohnungspolitischen Interessengruppen, sodass politikfeldexterne inklusionspolitische Interessen schwer Gehör finden. Zur Wohnberatung ließen sich keine aktiven politischen Prozesse nachzeichnen, die seit circa 20 Jahren bestehende Fachstelle für Wohnberatung weist eine große Pfadabhängigkeit auf und es gibt keine Akteure, die sich aufder Landesebene für eine Veränderung des Status Quo einsetzen. Als ergänzende informationelle Maßnahme gilt die geplante Kompetenzstelle Barrierefreiheit, für die sich Behindertenverbände seit dem Hessischen Aktionsplan des Jahres 2012 einsetzen und die im Jahr 2019 durch Bündnis 90/Die Grünen in den Koalitionsvertrag verhandelt worden ist. 


\subsubsection{Fazit}

Die empirischen Erkenntnisse werden im Anschluss vergleichend für Sachsen-Anhalt und Hessen zusammengefasst und an die AEP-Erklärungsfaktoren zurückgebunden (vgl. Kapitel 7.3). Übergeordnet für Hessen ist an dieser Stelle festzuhalten, dass der hessische wohnungspolitische Diskurs durch die Wohnraumknappheit im Rhein-MainGebiet dominiert wird. In diesem Kontext ist ein klarer "problem load « auf die Bezahlbarkeit von Wohnraum zu beobachten, weshalb es andere Zusatzinteressen wie die Barrierefreiheit schwer haben, sich durchzusetzen.

Insbesondere in der Bauordnungsnovellierung werden bezahlbarer und barrierefreier Wohnraum von der Wohnungs- und Bauwirtschaft als Zielkonflikt gerahmt. Hier stehen sich Angebotsseite und Nachfrageseite nach Wohnraum unversöhnlich gegenüber und die Widerstände, die mit regulativen staatlichen Eingriffen einhergehen, manifestieren sich deutlich. Die politischen Prozesse zur Wohnraumförderung verlaufen indessen weniger kontrovers und weniger öffentlichkeitswirksam. Hier tritt tendenziell die Wohnungs- und Bauwirtschaft als Veränderungsinteresse auf, wobei die Förderung von barrierefreiem Neubau bzw. barrierereduziertem Umbau nur ein sehr randständiges Förderthema darstellt. Im Detail zeigt sich indessen, dass die Angebotsseite von Wohnraum durchaus Zusatzförderungen für Aufzüge erfolgreich initiiert hat. Gleichzeitig entfiel mit der letzten Richtlinien-Überarbeitung die Zuschussförderung von eingeschränkt mit dem Rollstuhl zugänglichem Mietwohnraum. Generell spielten Sozialund Behindertenverbände in diesen Prozessen bislang keine Rolle und die parteipolitischen Akteure sind sich in dieser wenig konfliktbeladenen Anreizsteuerung relativ einig. Die zentrale Ausgestaltungskompetenz liegt bei den ministeriellen Fachabteilungen, welche die Richtlinien gemeinsam mit der WIBank und außerparlamentarischen Interessen - vor allem mit der Allianz für Wohnen - entwickeln. Schließlich spielen weiche informationelle Maßnahmen in Hessen bislang nur eine untergeordnete Rolle in der politischen Steuerung zum barrierefreien bzw. -reduzierten Wohnraum: Die Fachstelle für Wohnberatung gibt es seit circa 20 Jahren als pfadabhängige Struktur, zudem besteht seit dem Hessischen Aktionsplan des Jahres 2012 die Zielsetzung einer Kompetenzstelle Barrierefreiheit. Offensichtlich war dieses Vorhaben bislang nicht weit oben auf der politischen Agenda angesiedelt, hat aber durch den Koalitionsvertrag des Jahres 2019 eine deutlich verbesserte Chance zur Durchsetzung erfahren.

Insgesamt gibt es in Hessen keine Akteure, die barrierefreien bzw. -reduzierten Wohnraum generell ablehnen. Alle parteipolitischen Akteure und auch die Wohnungsund Bauwirtschaft bescheinigen dem Thema insbesondere durch den demografischen Wandel eine zunehmende Relevanz (IP 12: 6; IP 49: 3; IP 53: 5). Unterschiede finden sich allerdings in den Policy-Präferenzen, nach denen die Angebotsseite von Wohnraum eine ökonomische Förderung bevorzugt und die Behinderten- und Sozialverbände stärker einen verbindlichen regulativen Rahmen einfordern. Diese Scheidelinie setzt sich teilweise im parteipolitischen Spektrum fort. Dabei ist die Prioritätensetzung insgesamt durch »die aktuelle Marktlage« geprägt: »Da geht es wirklich vor allem um den bezahlbaren Wohnraum« (IP 47: 22, vgl. auch IP 10: 22; IP 15: 5; IP 18: 6; IP 20: 6). Eine Gesprächspartnerin aus der kommunalen Wohnraumförderung wird noch deutlicher und erklärt zur Stimme von Menschen mit Behinderungen und älteren Menschen in der aktuellen 
Wohnungspolitik: »[S]ie werden nicht gehört. [...] [W]enn Ihnen da irgendjemand [...] in irgendeinem Ministerium etwas anderes sagt, mit Verlaub, dann sagt er Ihnen nicht die Wahrheit « (IP 52: 59ff.).

Diesbezüglich zeigen die Problemstrukturen, dass die Auswirkungen des demografischen Wandels auf die Wohnungsmärkte in den 2000er und frühen 2010er Jahren durchaus aktiv politisch adressiert worden sind (vgl. Kapitel 7.2.2). Seit etwa Mitte der 2010er Jahre dominieren hingegen die Wohnraumknappheit und Bezahlbarkeit die Wohnungspolitik. Für den barrierefreien bzw. -reduzierten Wohnraum stellt diese Entwicklung ein Unmöglichkeitsfenster dar, was das Agenda-Setting und die Politikformulierung im Sinne einer stärkeren politischen Verankerung erschwert:

»Also, ich glaube im Moment ist [...] der Zug so ein bisschen abgefahren. Also, man hätte es vielleicht seinerzeit, als das aufkam, stärker in Angriff nehmen müssen, dann wäre es jetzt präsent. Aber man hat es nur so niederschwellig gehalten und deswegen sind jetzt andere Themen wie das Energetische oder überhaupt, dass Wohnungen fehlen, auf einmal viel wichtiger, als eben diese Barrierearmut« (IP 13: 61).

\subsection{Vergleichende Betrachtung und theoretische Rückbindung}

Bislang wurden die politischen Prozesse zum barrierefreien bzw. -reduzierten Wohnraum in Sachsen-Anhalt und Hessen getrennt analysiert. Forschungsleitend war die Frage B des Erkenntnisinteresses: Was erklärt das Zustandekommen bzw. Ausbleiben sowie die konkrete Ausgestaltung dieser Policies? Abschließend sollen die zentralen Erkenntnisse aus den beiden Fallstudien zusammengefasst und verglichen werden, wiederum orientiert an den fünf AEP-Erklärungsfaktoren. Wo finden sich landesspezifische Differenzen, wo bestehen Indizien für übergeordnete Muster?

\subsubsection{Instrumente und Instrumenten-Alternativen}

Der erste Erklärungsfaktor wurde in Policies im bestehenden Policy-Mix einerseits und Instrumenten-Alternativen andererseits differenziert (vgl. Kapitel 4.2). Im Anschluss an eine diesbezügliche Zusammenfassung sind die sogenannten ideologischen und institutionellen Filter zu diskutieren, die politische Maßnahmen auf dem Weg zu ihrer Durchsetzung zu durchlaufen haben.

Policies im bestehenden Policy-Mix

Der untersuchte Policy-Mix zeigt landesspezifische Besonderheiten. So wählt SachsenAnhalt im Bauordnungsrecht eine enge Anlehnung an die Musterbauordnung, während Hessen mit der 20-Prozent-Regelung einen Sonderweg formuliert und zugleich orientiert an dem Bundesmuster des Jahres 2016 die zuvor bestehende rollstuhlgerechte Zugänglichkeit streicht. Trotz hessischem Sonderweg ist das ARGEBAU-Muster für die politischen Prozesse in beiden Bundesländern ein zentraler Orientierungspunkt, Abweichungen davon bedürfen Begründungen. Damit werden die Änderungen in der 